\title{
Adsorption Ability for Toxic Chromium (VI) Ions in Aqueous Solution of Some Modified Oyster Shell Types
}

\author{
Thuy Chinh Nguyen $\mathbb{D}^{1,2}$ Xuan Thai Nguyen, ${ }^{1}$ Do Mai Trang Tran, ${ }^{2}$ Quoc Trung Vu, ${ }^{3}$ \\ Van Hai Nguyen, ${ }^{3}$ Duy Trinh Nguyen, ${ }^{4}$ Minh Thanh Do $\mathbb{D},{ }^{2}$ Thi Len Nguyen, ${ }^{5}$ \\ Thi Ngoc Lien Ly, ${ }^{5}$ and Hoang Thai $\mathbb{D}^{1,2}$ \\ ${ }^{1}$ Graduate University of Science and Technology, Vietnam Academy of Science and Technology, 18 Hoang Quoc Viet, Cau Giay, \\ Ha Noi 100000, Vietnam \\ ${ }^{2}$ Institute for Tropical Technology, Vietnam Academy of Science and Technology, 18 Hoang Quoc Viet, Cau Giay, \\ Ha Noi 100000, Vietnam \\ ${ }^{3}$ Faculty of Chemistry, Hanoi National University of Education, 136 Xuan Thuy Road, Cau Giay, Ha Noi 100000, Vietnam \\ ${ }^{4}$ Center of Excellence for Green Energy and Environmental Nanomaterials (CE GrEEN), Nguyen Tat Thanh University, \\ 300A Nguyen Tat Thanh District 4, Ho Chi Minh 755414, Vietnam \\ ${ }^{5}$ Hanoi University of Industry, 298 Cau Dien Street Bac Tu Liem District, Cau Giay, Ha Noi 100000, Vietnam
}

Correspondence should be addressed to Thuy Chinh Nguyen; thuychinhhn@gmail.com and Hoang Thai; hoangth@itt.vast.vn

Received 7 February 2020; Revised 8 June 2020; Accepted 13 July 2020; Published 27 July 2020

Academic Editor: Domenico Osella

Copyright (C) 2020 Thuy Chinh Nguyen et al. This is an open access article distributed under the Creative Commons Attribution License, which permits unrestricted use, distribution, and reproduction in any medium, provided the original work is properly cited.

\begin{abstract}
In this paper, the chromium, $\mathrm{Cr}(\mathrm{VI})$, ion adsorption ability of oyster shell samples collected from two sea regions in Vietnam (Phu Yen province and Quang Ninh province) was investigated and compared. The oyster shell samples were calcined at different temperatures and denatured by using ethylenediaminetetraacetic acid (EDTA). The Cr (VI) ion adsorption ability of the prismatic (PP) and nacreous (NP) shell layers of oysters was also evaluated. The characteristics of oyster shell samples before and after treatment were determined by using analysis methods including XRD, IR, BET, UV-Vis, and FESEM. The Langmuir, Freundlich, Temkin, and Dubinin-Radushkevich models and fit statistic equations were used to study the adsorption isotherms of Cr (VI) ion adsorption by oyster shells. The Cr (VI) ions adsorption kinetic has been set up using four reaction models consisting of firstorder, pseudo-first-order, second-order, and pseudo-second-order reaction models. Effects of experimental factors on the Cr (VI) ion adsorption process using oyster shells were also investigated and discussed in this work.
\end{abstract}

\section{Introduction}

Nowadays, the strong development of industry, agriculture, and services is leading to the pollution of water by various sources and directly affecting the environment and human health. Heavy metals pollution is one of the urgent issues, causing great impacts on people's life, health, and living. Pollution sources are commonly found in water basins near industrial parks, large cities, and mining areas. Water polluted by heavy metals has a negative impact on the living environment of organisms and humans because heavy metals can bioaccumulate in the food chain and penetrate into the human body.
Chromium, Cr, a very common and toxic heavy metal pollutant, is released into natural waters mainly from a variety of industrial wastewater sources. Hexavalent chromium, mainly found in the form of chromate $\left(\mathrm{CrO}_{4}{ }^{2-}\right)$ and dichromate $\left(\mathrm{Cr}_{2} \mathrm{O}_{7}{ }^{2-}\right)$, with its high ability to solute can accumulate in kidneys, stomach, and liver. Besides, it can cause gastrointestinal and dermatological problems as well as abnormal hematological functions [1]. The concentration of chromium in drinking water must be under $0.02 \mathrm{ppm}$. Therefore, it is important to treat the waterbodies to reduce or remove the pollutants. Recently, adsorption technology using common and abundant waste sources, for example, 
oyster shells [2], is becoming a popular solution in reducing and removing the pollutant from waterbodies thanks to its high efficiency and cost-effectiveness. Oysters are mollusks species of bivalve mollusks like mussels, scallops, and clams. They live on the coast or in coastal cliffs or estuaries and feed on plankton and creatures in mud, sand, sea water, etc. Being one of the most popular seafood dishes today, the amount of oyster shells released from seafood processing factories, seafood shops, and restaurants can be up to several tons/day. This creates a burden on the environment due to space taken for discarded shells and the odor from the remaining flesh. In the world, oyster shell was recycled for making new oyster reefs or returning these shells to the waterto restore native oysters. The oyster shell is primarily composed of calcium carbonate, but it also contains polysaccharides and minerals such as magnesium, calcium, sodium, iron, copper, nickel, and some other trace elements.Several studies have shown that oyster shells in different regions have different content of calcium carbonate and chemical composition [3-6]. Chemical and microstructure analysis showed that oyster shells account for about $90 \%$ of the total oyster weight and contain about $50 \%$ of calcium carbonate, so it is an appropriate material for manufacturing industries, lime, cement, and manure fertilizers, and other industries. For each material from different geographical location, the process of modification of materials will also be different [7-9]. Furthermore, oyster shells have been applied in the treatment of waste water [10], immobilization of arsenic in highly contaminated soils [11], immobilization of phosphorus in constructed wetlands [12], and adsorbing some metal ions such as $\mathrm{Cu}^{2+}$ and $\mathrm{Ni}^{2+}$ [13]. Most of the researches indicate promising results which can resolve some environmental issues and the disposal of oyster shells. However, application of oyster shells as an absorbent of $\mathrm{Cr}$ (VI) ion in aqueous solution has been not focused on in study. The use of oyster shells as absorbents for the removal of heavy metal ions in aqueous solution can be considered as one of the safe disposal ways because the chemicals used in treatment process of oyster shells can be reused many times and they were neutralized before being discharged into the environment without precipitates.

Although Vietnam has tropical climate, the north and south of Vietnam exhibit a different climate. Herein, there are four seasons in the north of Vietnam but there are only two seasons in the south of Vietnam. Unlikely natural conditions can lead to the variation of some characteristics of animals and vegetation in which they live. Biodiversity and life's environment have an important influence on the characterizations and adsorption ability of oyster shells. Quang Ninh province has a typical tropical climate for the north of Vietnam and Phu Yen province characterized for a typical tropical climate for the south of Vietnam. Therefore, in this work, two oyster shells collected at Quang Ninh province and Phu Yen province were selected to compare their adsorption ability for removal of $\mathrm{Cr}$ (VI) ion in aqueous solution. From the results, the geographical position and climatic influence on the characteristics of oyster shells were evaluated and compared. The IR, XRD, BET, and FESEM as well as Cr (VI) ion adsorption ability of the above oyster shells were investigated and discussed.

\section{Experimental}

2.1. Materials. Oyster shell (OS) samples were collected at Quang Ninh province sea, North Vietnam (coordinates in $20^{\circ} 54^{\prime} \mathrm{N} 107^{\circ} 12^{\prime} \mathrm{E}$ ) (designed as QNOS), and Phu Yen province sea, South Vietnam (coordinates in $12^{\circ} 09^{\prime} \mathrm{N}$ $109^{\circ} 11^{\prime} \mathrm{E}$ ) (designed as PYOS) (Figure 1). Both of these sea regions are in the East Sea.

Some other chemicals ( $\mathrm{NaClO}, \mathrm{NaOH}, \mathrm{K}_{2} \mathrm{Cr}_{2} \mathrm{O}_{7}, \mathrm{H}_{2} \mathrm{SO}_{4}$, 1,5-diphenylcarbazide (DCP), and ethylenediaminetetraacetic acid (EDTA)) were analytical chemicals and used as received.

2.2. Treatment of Oyster Shell Samples. Both QNOS and PYOS samples were treated as follows: The shells were washed with clean water and dried in a natural air convection oven until reaching the stable weight (OS-raw). The oyster shell contains prismatic (PP) and nacreous (NP) shell layers, and the PP shell layer has proved to have better $\mathrm{Cu}$ (II) ion adsorption ability than NP shell layer [9]. Based on some preliminary surveys about the $\mathrm{Cr}$ (VI) ions adsorption ability of the mixture of PP and NP shell layers of QNOS sample and compared to that of PP shell layer of QNOS sample, we recognized that the PP shell layers of QNOS sample have better $\mathrm{Cr}$ (VI) ions adsorption ability than the mixture of PP and NP shell layers. Therefore, in this work, PP shell layers were chosen for further study of the Cr (VI) ions adsorption ability.

Next, these shells were immersed in $\mathrm{NaClO}$ solution for 24 hours to remove sand and organic substances on the surface of $\mathrm{OS}$ before washing and drying at $100^{\circ} \mathrm{C}$ for 5 hours. Then, the shells were milled in $\mathrm{NaOH} / \mathrm{NaClO}$ solution (the ratio of OS/solution is $1 / 20 \mathrm{w} / \mathrm{v}$; the ratio of $\mathrm{NaOH}$ / $\mathrm{NaClO}$ is $5 / 1, \mathrm{v} / \mathrm{v}$ ) by a ball mill machine for 24 hours. After milling, the oyster shell particles were washed by distilled water and dried in a natural air convection oven until reaching the stable weight (OS-Na). The OS raw and OS-Na particles then were calcined at $750^{\circ} \mathrm{C}, 800^{\circ} \mathrm{C}$, and $900^{\circ} \mathrm{C}$ for 2 hours (OS-Na-calcined) on the Nabertherm furnace (Germany).

After that, these OS particles were applied for the removal of $\mathrm{Cr}$ (VI) ion in aqueous solution. Based on the best highest $\mathrm{Cr}$ (VI) ion absorption ability, the OS particles will be chosen for modification surface by EDTA in $50 \mathrm{~mL}$ of distilled water with the OS/EDTA ratio of $10 / 1(\mathrm{w} / \mathrm{w})$ at $60^{\circ} \mathrm{C}$ for 2 hours. The abbreviation of OS samples is shown in Table 1. The suggested scheme and reaction for synthesis OS samples are shown in Figure 2.

2.3. Chromium (VI) Ion Absorption Ability in Aqueous Solution by Oyster Shell Particles. Preparation of $0.5 \%$ solution of 1,5-diphenylcarbazide (DCP): 0.5 grams of DCP was dissolved in $100 \mathrm{~mL}$ acetone (solvent) and stored in a dark bottle at $4^{\circ} \mathrm{C}$. 


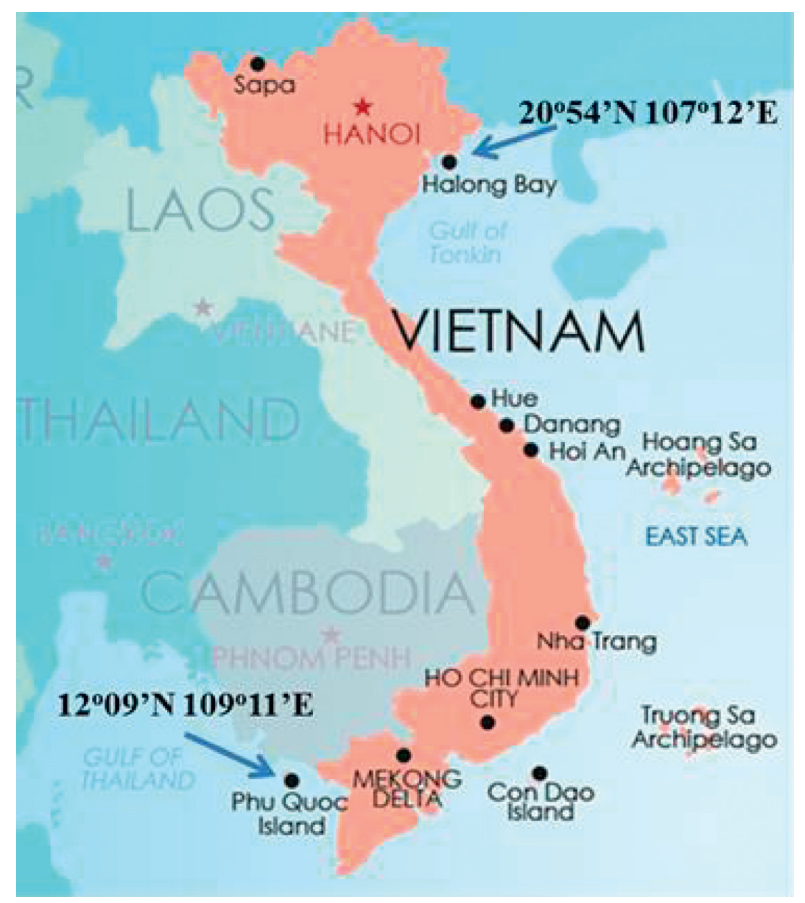

Figure 1: Positions for collecting oyster shells.

Preparation of Cr (VI) ion solution $1000 \mathrm{ppm}: 2.829$ grams of $\mathrm{K}_{2} \mathrm{Cr}_{2} \mathrm{O}_{7}$ was dissolved in $1 \mathrm{~L}$ of distilled water and stored in dark bottle at low temperature.

$\mathrm{Cr}$ (VI) ion adsorption process by OS samples as follows: 0.5 grams of OS particles was added into $100 \mathrm{~mL}$ of $\mathrm{Cr}$ (VI) ion solution. This mixture was stirred continuously on the magnetic stirrer for 2 hours. Then, it was filtered by a filter paper and $25 \mathrm{~mL}$ of filtered solution was withdrawn into a $50 \mathrm{~mL}$ glass flask. Next, $1 \mathrm{~mL}$ of $\mathrm{H}_{2} \mathrm{SO}_{4} 1 \mathrm{M}$ solution and $1 \mathrm{~mL}$ of DCP solution were introduced into the filtered solution and this solution was kept stable for 10 minutes to obtain a red purple solution caused by reaction of $\mathrm{Cr}$ (VI) ions and DCP. Finally, this red purple solution was taken on an Ultraviolet-Visible (UV-Vis) Spectrophotometer (CINTRA 40, GBC, USA) at maximum wavelength $\left(\lambda_{\max }\right)$ of $540 \mathrm{~nm}$ to determine the absorbance of $\mathrm{Cr}$ (VI) ions solution.

2.3.1. Adsorption of Cr (VI) Ion by OS Samples. The amount of $\mathrm{Cr}$ (VI) ions adsorbed per gram of adsorbent was calculated using the following equation:

$$
Q=\frac{\left(C_{0}-C_{e}\right) \cdot V}{W},
$$

where $Q$ is the amount of $\mathrm{Cr}$ (VI) ions absorbed per amount of adsorbent at equilibrium condition $(\mathrm{mg} / \mathrm{g}), C_{0}$ and $C_{\mathrm{e}}$ are the initial and equilibrium concentration of metal ion in solution $\left(\mathrm{mg} \mathrm{L}^{-1}\right), V$ is the volume of solution $(L)$, and $W$ is the sorbent mass $(g)$.

The removal of metal ion was calculated using the following equation:

$$
H=\frac{\left(C_{0}-C_{\mathrm{e}}\right) \cdot 100}{C_{0}},
$$

where $H$ is the percentage of removed metal ion, \%.

The equilibrium concentration of $\mathrm{Cr}$ (VI) ions in solution $\left(C_{\mathrm{e}}\right)$ was calculated based on the calibration equation of $\mathrm{Cr}$ (VI) ions in aqueous solution at $\lambda_{\max }$ of $540 \mathrm{~nm}$ as follows:

$$
y=0.4609 x+0.0378
$$

where $y$ is the absorbance of $\mathrm{Cr}$ (VI) ions in aqueous solution and $x$ is the concentration of $\mathrm{Cr}$ (VI) ions in aqueous solution (the linear regression coefficient, $R^{2}=0.9991$ ).

Some factors which can influence $\mathrm{Cr}$ (VI) ions adsorption ability by OS samples were investigated, including the $\mathrm{pH}$ of solution (by varying the volume of $\mathrm{H}_{2} \mathrm{SO}_{4} 1 \mathrm{M}$ solution to change $\mathrm{pH}$ of solution from 2 to 7 ), OS weight (changed from 0.1 to 1.0 gram), adsorption time (changed from 20 to 180 minutes), and $\mathrm{Cr}$ (VI) ions concentration (changed from 3 to $15 \mathrm{ppm}$ ).

Although 20 samples of oyster shells were treated as listed in Table 1 , there are only 4 samples (QNOS-PP-800, QNOS-PP-800-EDTA, PYOS-PP-Na-800, and PYOS- PPNa-800-EDTA) exhibiting a good Cr (VI) ions adsorption ability. Therefore, 4 OS samples were focused on characterization and compared to initial samples (QNOS-PP and PYOS-PP).

2.3.2. Study on Adsorption Isotherms. In this work, Langmuir, Freundlich, Temkin, and Dubinin-Radushkevich isotherms have been selected for study of $\mathrm{Cr}$ (VI) ions adsorption behavior in solid-liquid system.

The Langmuir isotherm equation for ion adsorption can be written as follows:

$$
Q_{e}=\frac{Q_{0} k_{\mathrm{L}} C_{\mathrm{e}}}{1+k_{\mathrm{L}} C_{\mathrm{e}}}
$$

where $Q_{\mathrm{e}}$ is the amount of $\mathrm{Cr}(\mathrm{VI})$ ions absorbed per amount of adsorbent at equilibrium ( $\mathrm{mol} / \mathrm{g}$ ) and $C_{\mathrm{e}}$ is the equilibrium concentration of the solute $(\mathrm{mol} / \mathrm{L})$. The $Q_{0}$ and $k_{\mathrm{L}}$ are the Langmuir constants, where $Q_{0}$ represents the maximum monolayer adsorption capacity and $k_{\mathrm{L}}$ represents binding energy or affinity parameter of the adsorption system.

The Freundlich isotherm is expressed as

$$
Q_{e}=k_{F} C_{e}^{(1 / n F)},
$$

where $k_{\mathrm{F}}$ is Freundlich isotherm constant $\left(\mathrm{L}^{1 / \mathrm{n}} \mathrm{mg}^{(1-1 / n)} \mathrm{g}^{-1}\right)$ and $1 / n_{\mathrm{F}}$ is the Freundlich exponent.

The Temkin isotherm equation is described as follows:

$$
Q_{e}=B \ln A_{T}+B \ln C_{e},
$$

with $B=\mathrm{R}_{T} / b_{T}$, where $A_{T}$ is Temkin isotherm equilibrium binding constant $(\mathrm{L} / \mathrm{g}), b_{T}$ is Temkin isotherm constant, $\mathrm{R}$ is universal gas constant $(\mathrm{R}=8.314 \mathrm{~J} / \mathrm{mok} / \mathrm{K})$, and $\mathrm{T}=298 \mathrm{~K}$.

The Dubinin-Radushkevich (DR) isotherm equation is

$$
\ln Q_{e}=\ln Q_{S}-K^{a d \varepsilon^{2}}
$$


TABLE 1: Signature of oyster shell samples.

\begin{tabular}{lcc}
\hline No. & Sample & Abbreviation of sample \\
\hline 1 & Prismatic shell layer of Quang Ninh oyster shells & QNOS-PP \\
2 & QNOS-PP calcined at $800^{\circ} \mathrm{C}$ & QNOS-PP-800 \\
3 & QNOS-PP-800 modified with EDTA & QNOS-PP-800-EDTA \\
4 & Prismatic shell layer of Phu Yen oyster shells & PYOS-PP \\
5 & PYOS-PP treated with NaClO and ball milled in NaOH/NaClO solution & PYOS-PP-Na \\
6 & PYOS-PP-Na calcined at $750^{\circ} \mathrm{C}$ & PYOS-PP-Na-750 \\
7 & PYOS-PP-Na calcined at $800^{\circ} \mathrm{C}$ & PYOS-PP-Na-800 \\
8 & PYOS-PP-Na calcined at $900^{\circ} \mathrm{C}$ & PYOS-PP-Na-900 \\
9 & PYOS-PP-Na-800 modified with EDTA & PYOS-PP-Na-800-EDTA \\
\hline
\end{tabular}

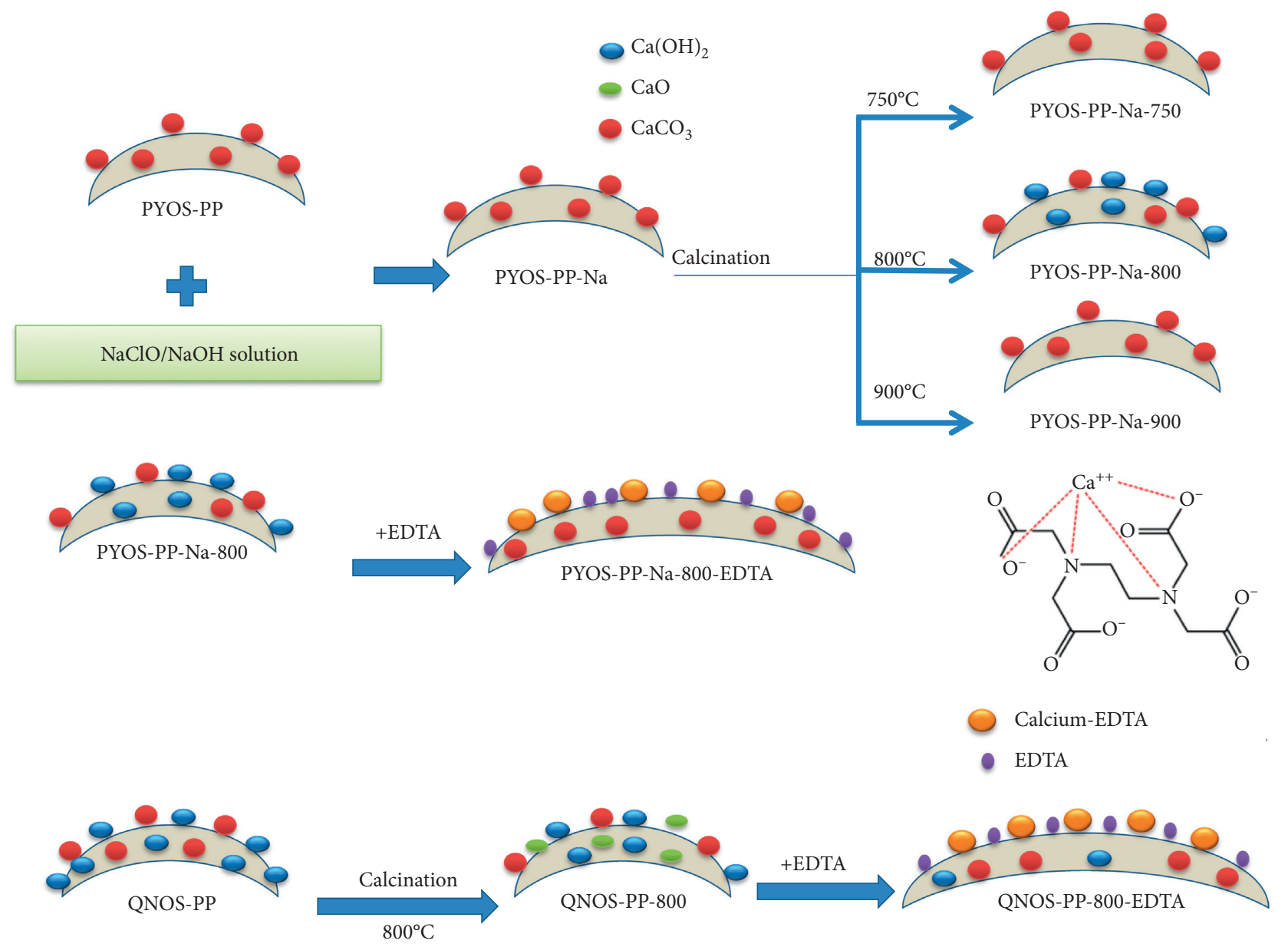

FIgURE 2: The suggested scheme and reaction for the synthesis of the OS samples.

with $\varepsilon=\mathrm{RT} \ln (1+1 / \mathrm{Ce})$, where $Q$ s is the theoretical isotherm saturation capacity (mg/g) and $K^{\text {ad }}$ is Dubinin-Radushkevich isotherm constant $(\mathrm{mol} 2 / \mathrm{kJ} 2)$.

2.3.3. Study on Adsorption Kinetics. In this work, first-order, pseudo-first-order, second-order, and pseudo-second-order reaction model have been selected for study on ion adsorption kinetics.

First-order reaction model is as follows:

$$
\ln C_{t}=\ln C_{0}-k_{1} t
$$

Pseudo-first-order reaction model is as follows:

$$
\ln \left(Q_{0}-Q_{t}\right)=\ln Q_{0}-k_{s 1} t
$$

Second-order reaction model is as follows:

$$
\frac{1}{C_{t}}=\frac{1}{C_{0}}+k_{2} t
$$

Pseudo-second-order reaction model is as follows:

$$
\frac{1}{\left(Q_{e}-Q_{t}\right)}=\frac{1}{Q_{e}}+k t \Longrightarrow \frac{t}{Q_{t}}=\frac{1}{h}+\frac{1}{Q_{e}} t,
$$

with $h=\mathrm{kQ}_{\mathrm{e}}{ }^{2}$, where $C_{0}$ and $C_{\mathrm{t}}$ are the concentration of the solute at the initial time and the testing time $t(\mathrm{mg} / \mathrm{L}) ; Q_{0}$ is 
the maximum monolayer coverage capacity $(\mathrm{mg} / \mathrm{g}) ; Q_{\mathrm{t}}$ and $Q_{e}$ are the amount of metal ions adsorbed per gram of adsorbent at testing time $t$ and at equilibrium $(\mathrm{mg} / \mathrm{g}) ; k_{1}$, $k_{\mathrm{s} 1}, k_{2}$, and $k$ are first-order reaction model, pseudo-firstorder reaction model, second-order reaction model, and pseudo-second-order reaction model constant, respectively.

2.4. Characterizations. Infrared (IR) spectroscopy: IR spectra of samples were recorded using a Nicolet iS10 spectrometer (Thermo Scientific, USA) at room temperature in 400 to $4000 \mathrm{~cm}^{-1}$ wavenumber range by 32 scans averaging with $8 \mathrm{~cm}^{-1}$ resolution.

Field emission scanning electron microscopy (FESEM): FESEM images of samples in solid state were taken by using a S-4800 FESEM machine (Hitachi, Japan).

X-ray diffraction (XRD) analysis: XRD patterns of samples were performed on a Siemens D5000 X-ray Diffractometer (XRD) with $\mathrm{CuK}_{\alpha}$ radiation source $(\lambda=0.154 \mathrm{~nm})$ at $40 \mathrm{kV}$ generator voltage with $0.03^{\circ}$ step and $30 \mathrm{~mA}$ current by $0.043^{\circ} / \mathrm{s}$ scan speed in the range of $2 \theta$ from $2^{\circ}$ to $70^{\circ}$.

Brunauer-Emmett-Teller (BET) isotherm equation: specific surface area of samples was calculated from data by nitrogen adsorption-desorption method on a Tristar $3000 \mathrm{~V}$ 6.07 A device (Micromeritics Instrument Corporation).

The $\mathrm{pH}$ zero point charge $\left(\mathrm{pH}_{\mathrm{zpc}}\right)$ of OS samples has been measured by the electrochemical method [14]. $50 \mathrm{~mL}$ of a $0.01 \mathrm{M} \mathrm{NaCl}$ solution was placed in $100 \mathrm{~mL}$ glass flasks. Next, the $\mathrm{pH}$ of $\mathrm{NaCl}$ solution was firstly adjusted to successive initial values between 2 and 12 by using either $0.1 \mathrm{M}$ $\mathrm{HCl}$ or $0.1 \mathrm{M} \mathrm{NaOH}$ solutions and 0.15 grams of OS samples was added to the solutions. The final $\mathrm{pH}$ was measured after a 48-hour testing period. The final $\mathrm{pH}$ values were plotted against the initial $\mathrm{pH}$ and $\mathrm{pH}_{\mathrm{ZPC}}$ was taken at which the curve crosses the line $\mathrm{pH}(($ final $)=\mathrm{pH}$ (initial)). The measures of $\mathrm{pH}$ have been made using a $\mathrm{pH}$-meter (Hanna Instruments).

2.5. Error Analyzation. In this paper, apart from using the $\mathrm{R}$-square method (square of the correlation between the response values and the predicted response values), we also apply other loss functions such as sum of squared error (SSE); mean squared error (MSE); and root mean squared error (RMSE) to determine the most suitable isotherms/ kinetics model which can represent the adsorption process of $\mathrm{Cr}$ (VI) ions using oyster shells:

Sum of squared error (SSE): this statistic is the total deviation of the response values from the fit to the response values:

$$
\mathrm{SSE}=\operatorname{Sum}_{(i=1 \text { to } n)}\left\{\left(y_{i}-f_{i}\right)^{2}\right\}
$$

Mean squared error (MSE): mean of total error is given by

$$
\mathrm{MSE}=\frac{\mathrm{SSE}}{n}
$$

Root mean squared error (RMSE): root of mean squared error of fit standard error is given as

$$
\mathrm{RMSE}=(\mathrm{MSE})^{1 / 2}
$$

where $y_{\mathrm{i}}$ is the response value; $f_{\mathrm{i}}$ is the predicted response value, and $n$ is the number of obtained values.

\section{Results and Discussion}

\subsection{Characterization of Some Oyster Shell Samples}

3.1.1. IR Spectra of Some Oyster Shell Samples. Figure 3 and Table $1 S$ present IR spectra and characteristic wavenumbers for vibrations of functional groups of the surveyed OS samples. The position of characteristic peaks of all OS samples in the IR spectra is similar. For example, the peaks at wavenumbers about $3400 \mathrm{~cm}^{-1}$ and $1630 \mathrm{~cm}^{-1}$ are characterized for the valence oscillation and deformation fluctuations of $\mathrm{OH}$ groups in hydrogen bonds. The weak peak at $2512 \mathrm{~cm}^{-1}$ is specific to the valence oscillation of $\mathrm{CO}_{3}{ }^{2-}$ group. The characteristic peaks for oscillation of $\mathrm{C}-\mathrm{O}$ $\left(875 \mathrm{~cm}^{-1}\right)$ and $C=O\left(1798 \mathrm{~cm}^{-1}\right)$ groups are also shown in IR spectra of the surveyed OS samples. Some weak peaks specific to oscillation of group $\mathrm{CH}$ (at $2872-2985 \mathrm{~cm}^{-1}$ ) may be due to the existence of organic impurities in the OS or $\mathrm{CH}$ group in EDTA grafted onto the OS surface after modification process.

From IR spectra of the QNOS and PYOS samples, it can be seen that the treatment process with $\mathrm{NaClO} / \mathrm{NaOH}$ solution or calcination has negligible effect on the functional groups in OS samples. Comparing the IR spectra of the OS samples collected in Quang Ninh and Phu Yen province sea regions, a difference for the band at $3640 \mathrm{~cm}^{-1}$ with strong intensity in the IR spectra of Quang Ninh OS samples (QNOS-PP, QNOS-PP-800, and QNOS-PP-800-EDTA) can be observed. It is assigned to fluctuation of valence of $\mathrm{OH}$ group which is not involved in hydrogen bonding. Thus, the IR spectra of investigated OS samples also show that biodiversity and geographical position have an influence on their functional groups.

3.1.2. Crystal Structure of Some Oyster Shell Particles. XRD pattern of QNOS-PP particles indicates the calcite rhomboid crystal structure of $\mathrm{CaCO}_{3}$ and hexagonal portlandite crystal of $\mathrm{Ca}(\mathrm{OH})_{2}$ (Figure $4(\mathrm{a})$ ). In the QNOS-PP sample, there are two crystal phases; among them, the calcite crystals appeared at d-spacing of $3.037 \AA$, while the portlandite crystals were found at d-spacing of $4.94 \AA$. The intensity for diffraction peak of portlandite crystals is significantly stronger than that of the calcite crystals; the resulting portlandite crystals account for most of the crystalline structure of QNOS-PP sample. 


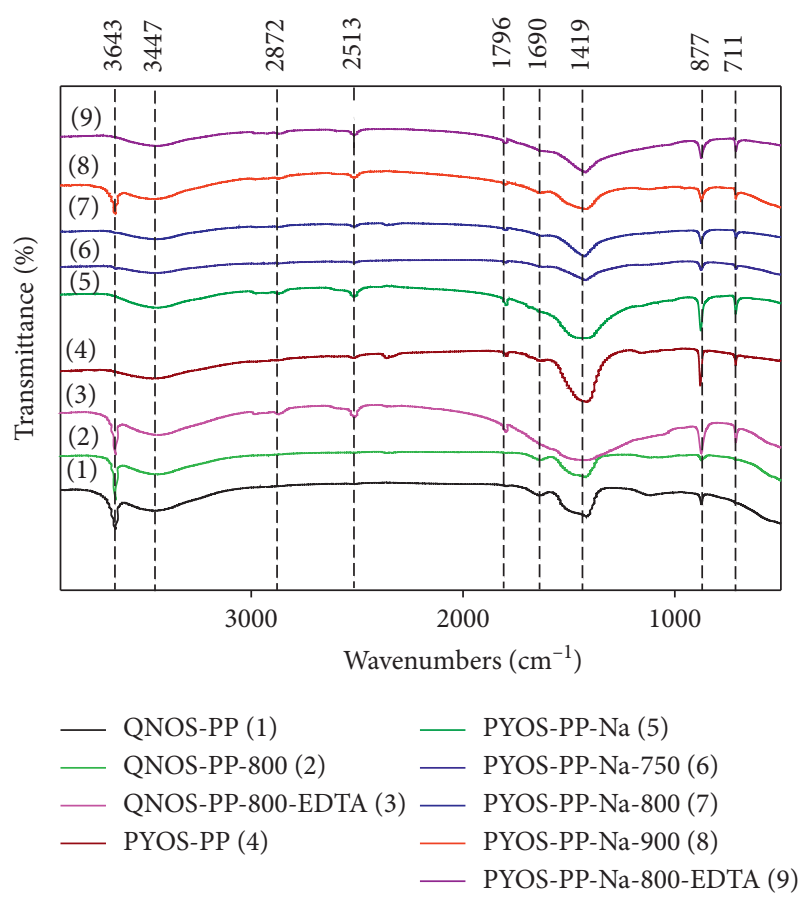

FIGURE 3: IR spectra of PYOS and QNOS samples.

After treatment of QNOS-PP sample by $\mathrm{NaClO} / \mathrm{NaOH}$ solution and calcination at $800^{\circ} \mathrm{C}$, the crystal structure of QNOS-PP sample was changed significantly (Figure 4(b)). Besides the existence of calcite and portlandite crystals, the appearance of cubic calcium oxide crystals with $d=2.405 \mathrm{~nm}$ displays that $\mathrm{CaO}$ was formed as a new phase after the calcination process at high temperature. $\mathrm{CaCO}_{3}$ and $\mathrm{Ca}(\mathrm{OH})_{2}$ were pyrolysed and $\mathrm{CaO}$ was formed. The change in the phase structure of this OS sample after calcination has a significant influence on $\mathrm{Cr}$ (VI) ion adsorption ability as discussed above.

After modification of QNOS-PP-Na-800 sample by EDTA, the position and intensity of the characteristic diffraction peaks for $\mathrm{CaCO}_{3}$ and $\mathrm{Ca}(\mathrm{OH})_{2}$ are almost unchanged but the peaks for $\mathrm{CaO}$ are absence and the intensity of peaks characterized for $\mathrm{Ca}(\mathrm{OH})_{2}$ was decreased (Figure 4(c)). The diffraction peak of $\mathrm{Ca}(\mathrm{OH})_{2}$ in XRD pattern of QNOS-PP-Na-800 sample at position $d=4.916 \mathrm{~nm}$ was slightly shifted to position $d=4.943 \mathrm{~nm}$ in the XRD pattern of QNOS-PP-Na-800-EDTA sample. This indicates that EDTA reacted with $\mathrm{CaO}$ and $\mathrm{Ca}(\mathrm{OH})_{2}$ in QNOS-PP-Na-800 particles through the reaction between the $-\mathrm{COOH}$ groups of EDTA and $\mathrm{Ca}(\mathrm{OH})_{2}$ or $\mathrm{CaO}$ as the following equations:

$$
\begin{array}{r}
\mathrm{Ca}(\mathrm{OH})_{2}+\mathrm{EDTA}=\mathrm{Ca}(\text { EDTA })+\mathrm{H}_{2} \mathrm{O} \\
\mathrm{CaO}+\mathrm{EDTA}=\mathrm{Ca}(\text { EDTA })+\mathrm{H}_{2} \mathrm{O}
\end{array}
$$

In the XRD pattern of PYOS-PP sample, only the occurrence of rhombocalcite crystals is observed (Figure 5(a)). Compared to the crystal structure of QNOS-PP sample in Figure 4(a), it can be seen that two samples of OS collected in Quang Ninh and Phu Yen province sea areas have distinctly different crystal structures. This explains the difference in the $\mathrm{Cr}$ (VI) ion adsorption capacity of the investigated OS samples. Herein, biodiversity and geographical position are important factors and should be investigated for the same material collected at different geographical regions and aquaculture conditions of oysters.

After treatment of PYOS-PP sample with $\mathrm{NaClO} / \mathrm{NaOH}$ solution, the position of diffraction peaks for calcite in the XRD pattern of PYOS-PP-Na (Figure 5(b)) is similar to that of PYOS-PP. However, the intensity of these peaks was slightly decreased. When calcinating at $800^{\circ} \mathrm{C}$, additional diffraction peaks with strong intensity were characterized for the hexagonal portlandite crystal of $\mathrm{Ca}(\mathrm{OH})_{2}$ in the PYOSPP-Na-800 sample (Figure 5(c)).

At different temperatures of calcination, the crystal structure of PYOS is affected significantly. For instance, at $750 \mathrm{C}$ and $800 \mathrm{C}$, the portlandite crystals appeared with stronger intensity than calcite crystals, while at $900 \mathrm{C}$, the calcite crystals are occupied (Figures 5(c), 5(d), and 5(e)). The change in crystal structure of calcinated PYOS causes the difference in $\mathrm{Cr}$ (VI) ions adsorption ability of these samples.

Observing the XRD pattern of the PYOS-PP-Na-800EDTA sample, only diffraction peaks of calcite crystals appeared (Figure 5(f)). This may be due to portlandite crystals formed after the calcination process has been rinsed in the denaturing process with EDTA.

The data of crystal size for the OS samples which were calculated according to Scherer equation based on the data of diffraction peaks on XRD diagram demonstrated that the crystal sizes of calcite, portlandite, and calcium oxide crystals are varied significantly (Table 2). Thus, the treatment process of OS samples not only influences the crystal phases but also affects the crystal size of these OS samples.

3.1.3. Special Surface Area of Some Oyster Shell Samples. Table 3 and Figures 6 and 7 display nitrogen adsorption isotherm-desorption isotherm and parameters such as specific surface area (BET), capillary volume, and capillary diameter of the investigated OS samples. Compared to the IUPAC classification of adsorption isotherms, nitrogen adsorption lines and desorption lines of OS samples follow type III. Based on De Boer analysis, the OS samples have capillaries in the inclined slit pore form and almost no microcapillaries (the value of microcapillary area and volume in Table 3 are very small).

Comparing the data in Table 3, it can be seen that the samples of QNOS-PP and PYOS-PP have significant differences in specific surface area as well as pore volume and pore diameter. For OS samples collected in Quang Ninh sea region, after heat treatment, the crystal structure variation is an important reason leading to the change in the specific surface area of the QNOS-PP-800 sample. The pore diameter of this material was increased significantly, and this increase can result in an improvement in $\mathrm{Cr}$ (VI) ions absorption ability.

After modification of QNOS-PP-800 sample with EDTA, the specific surface area, capillary volume, and capillary 


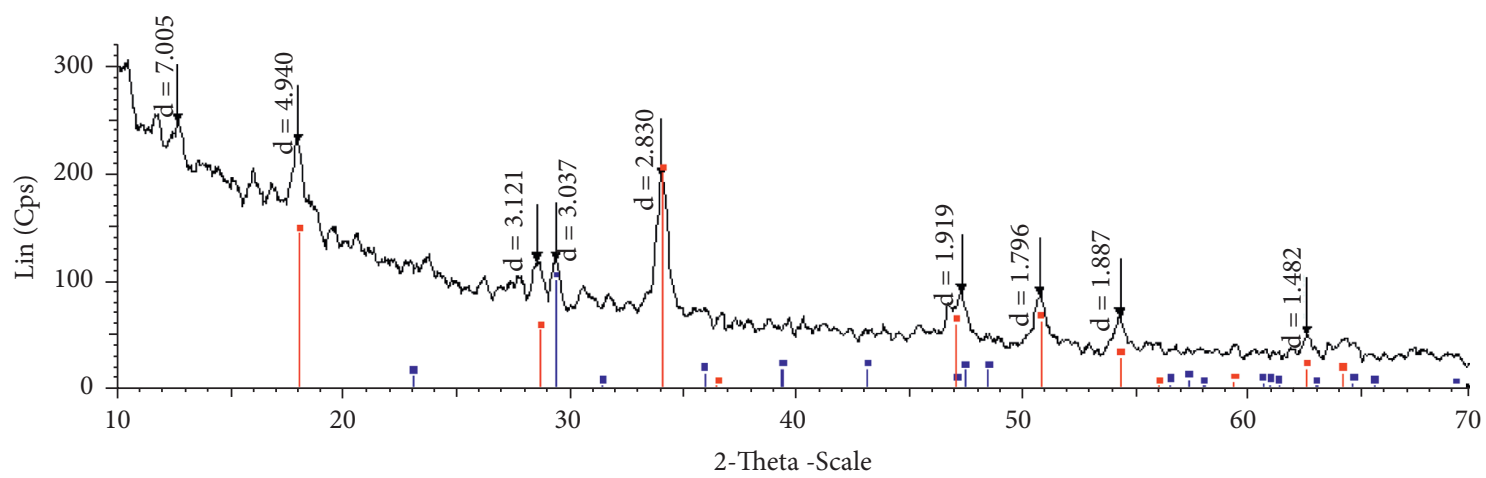

$\square$ 00-044-1481 $\left({ }^{*}\right)$ - portlandite, syn - $\mathrm{Ca}(\mathrm{OH})_{2}$

口 00-005-0586 $\left(^{*}\right)$ - calcite, syn - $\mathrm{CaCO}_{3}$

(a)

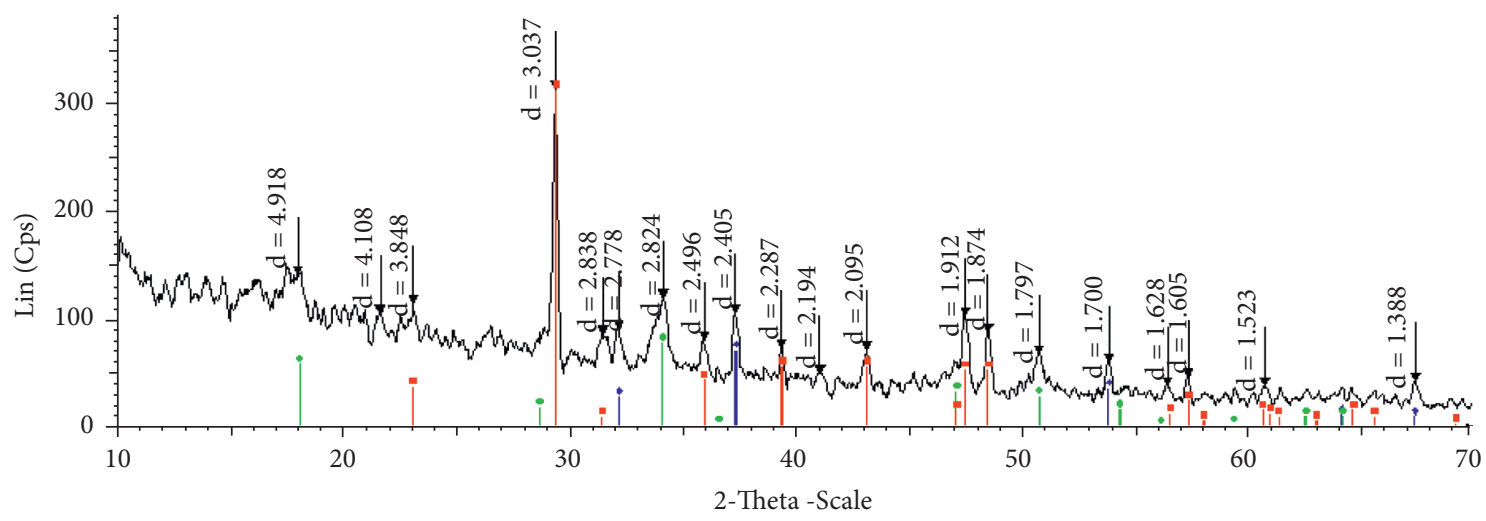

口 00-005-0586 $\left({ }^{*}\right)$ - calcite, syn - $\mathrm{CaCO}_{3}$

口 00-048-1467 (C) - calcium Oxide - $\mathrm{CaO}$

回 00-004-0733 (I) - portlandite, syn - $\mathrm{Ca}(\mathrm{OH})_{2}$

(b)

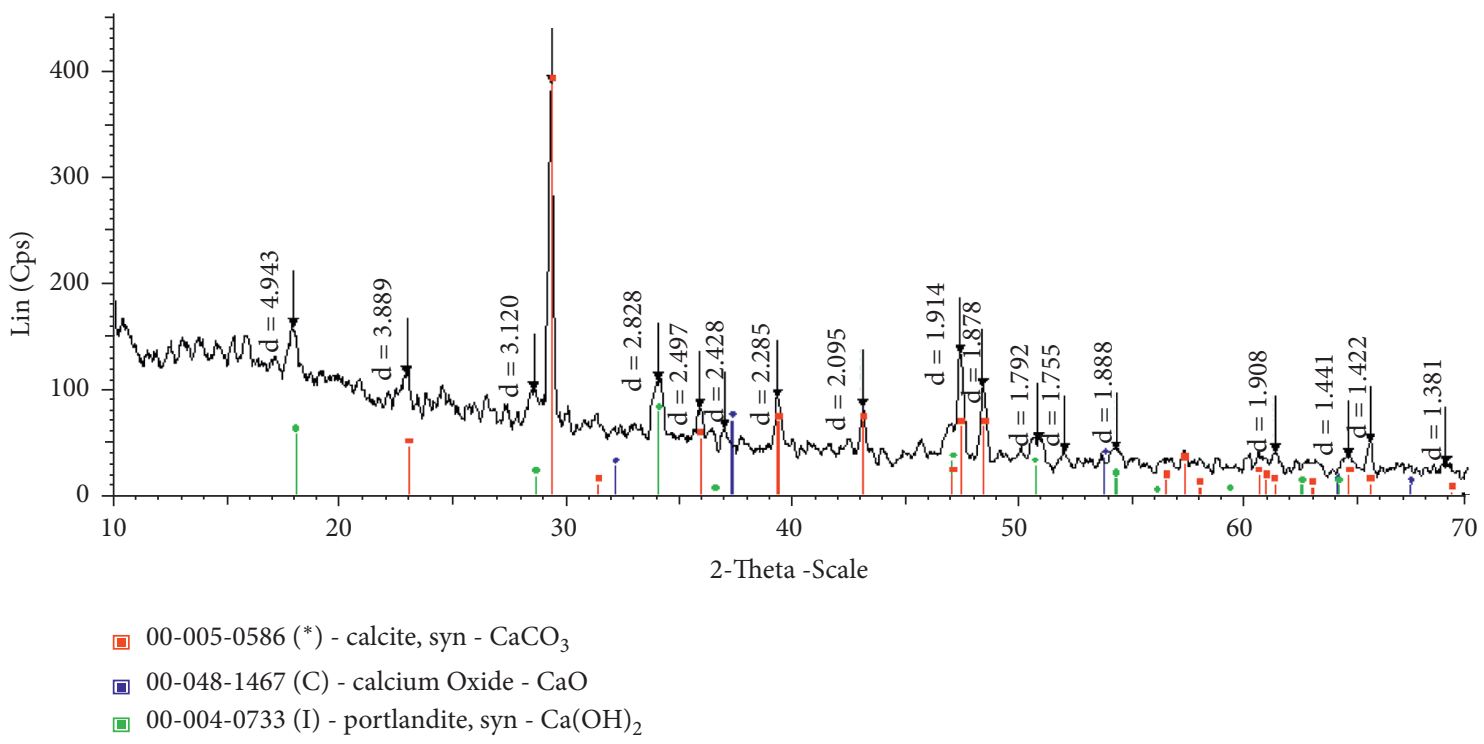

(c)

FIGURE 4: XRD patterns of QNOS-PP (a), QNOS-PP-Na-800 (b), and QNOS-PP-800-EDTA (c) samples. 


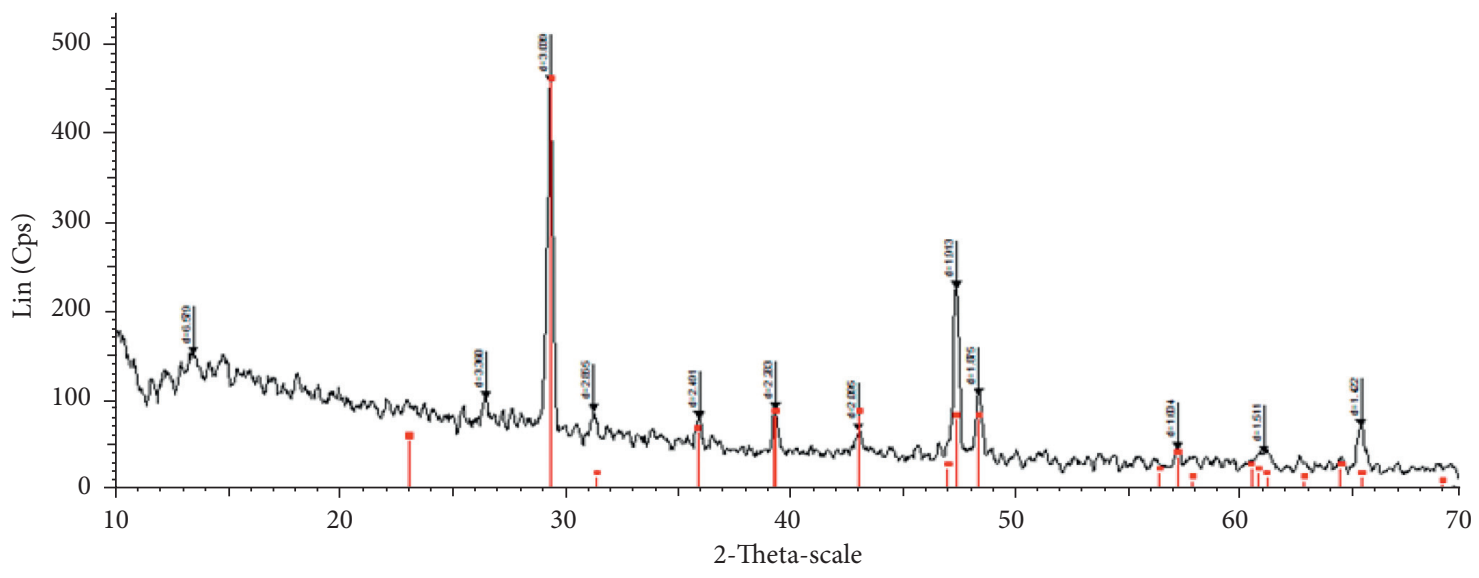

$\square$ 00-005-0586 (*) - Calcite, syn - $\mathrm{CaCO}_{3}$

(a)

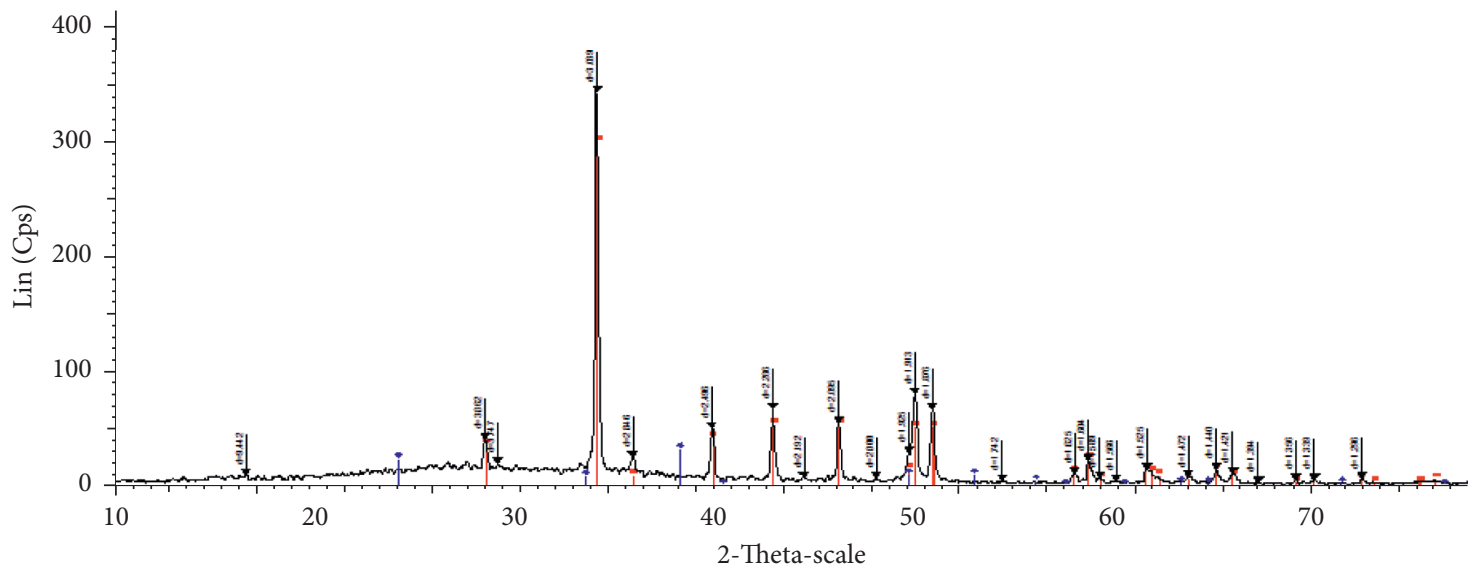

口 00-044-1481 (*) - Portlandite, syn - $\mathrm{Ca}(\mathrm{OH})_{2}$

口 00-005-0586 $\left({ }^{*}\right)$ - Calcite, syn - $\mathrm{CaCO}_{3}$

(b)

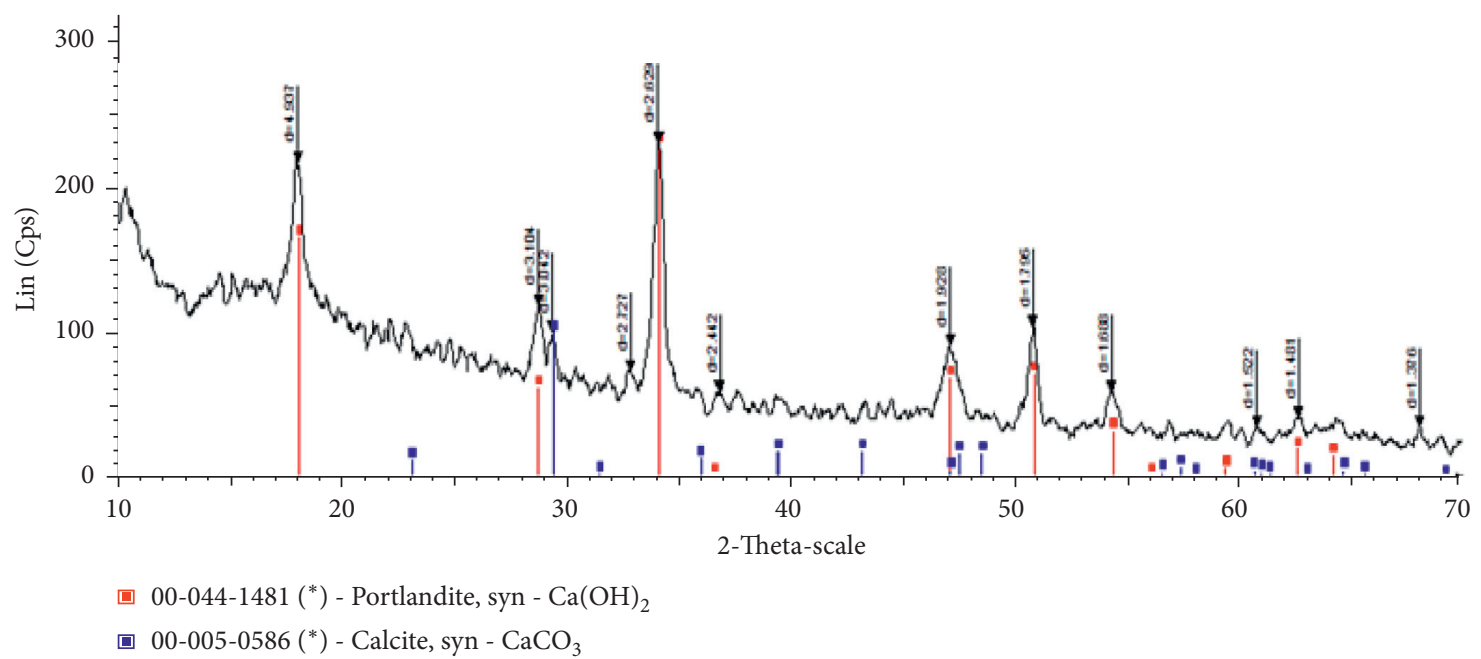

(c) 


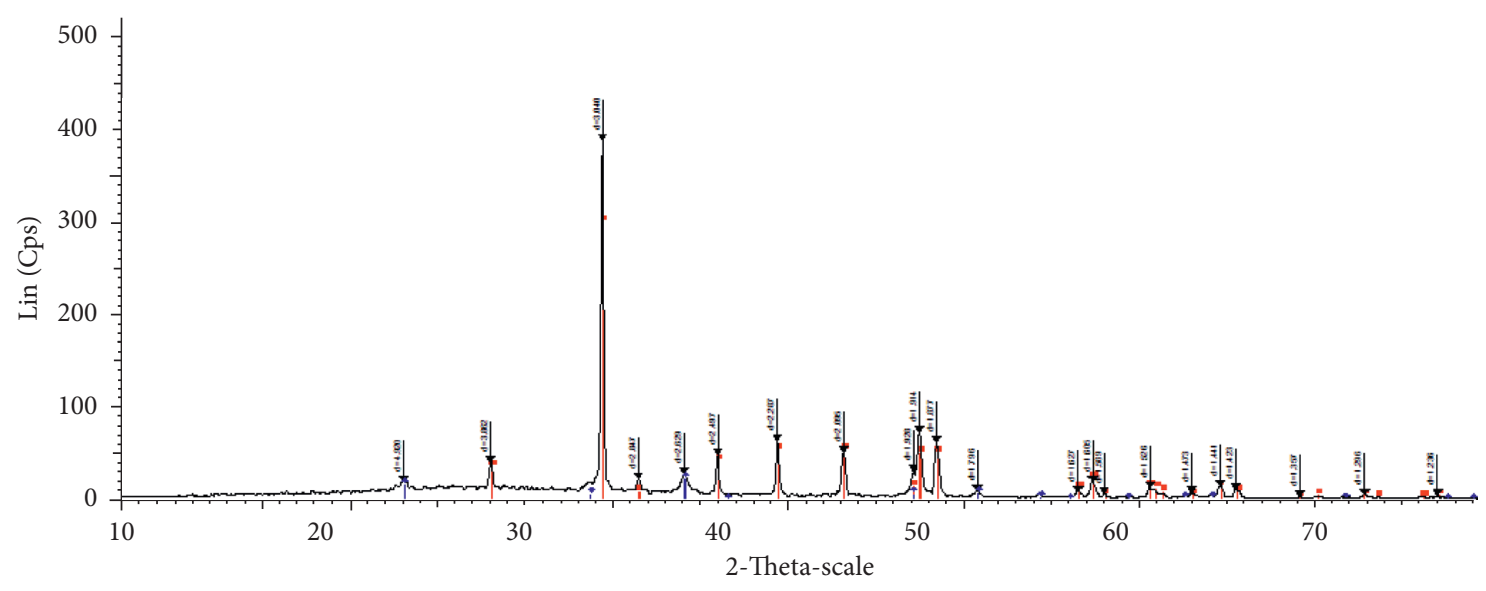

■ 00-044-1481 $\left({ }^{*}\right)$ - Portlandite, syn - $\mathrm{Ca}(\mathrm{OH})_{2}$

口 00-005-0586 (*) - Calcite, syn - $\mathrm{CaCO}_{3}$

(d)

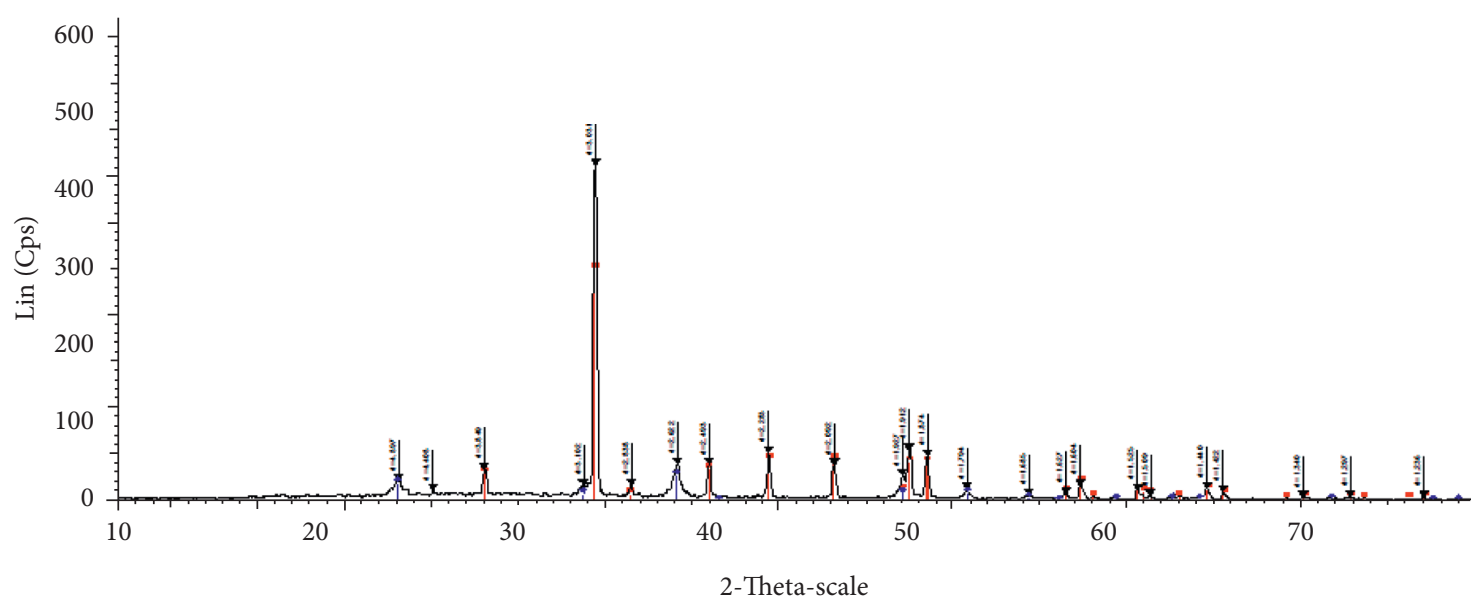

$\square$ 00-044-1481 (*) - Portlandite, syn - $\mathrm{Ca}(\mathrm{OH})_{2}$

$\square$ 00-005-0586 (*) - Calcite, syn - $\mathrm{CaCO}_{3}$

(e)

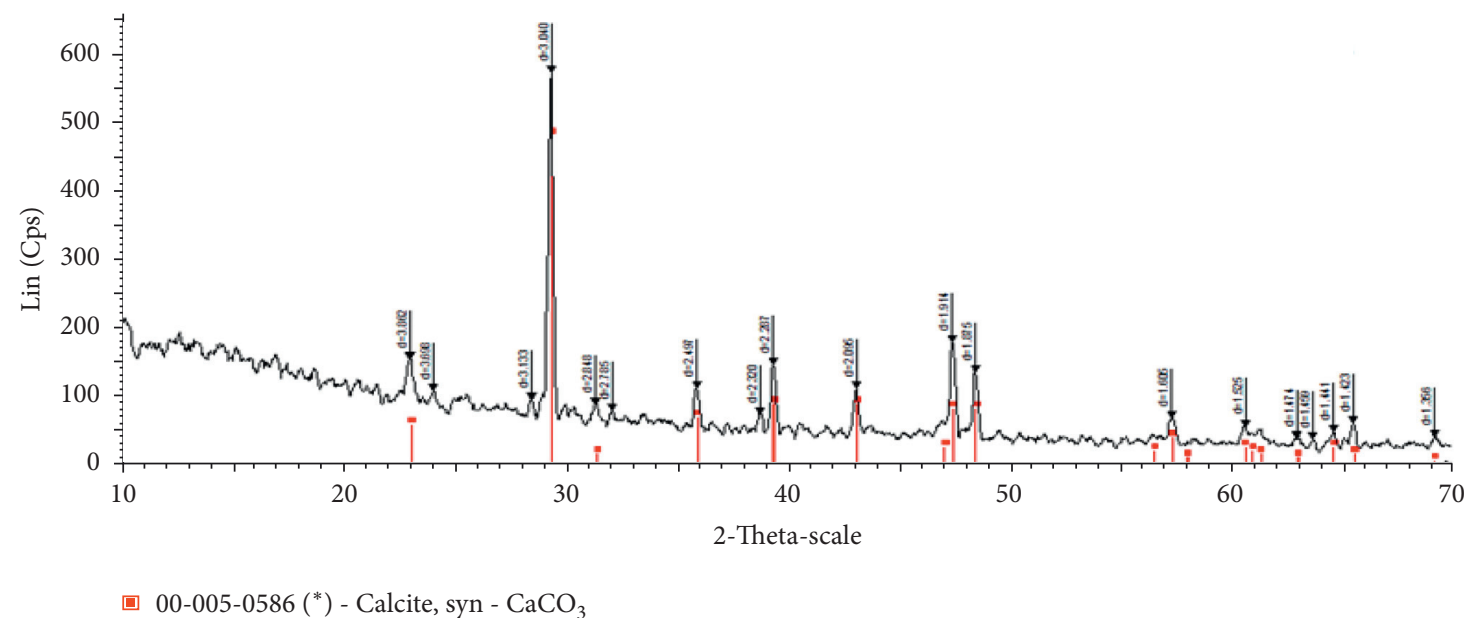

(f)

FIGURE 5: XRD patterns of PYOS-PP (a), PYOS-PP-Na (b), PYOS-PP-Na-800 (c), PYOS-PP-Na-750 (d), PYOS-PP-Na-900 (e), and PYOSPP-Na-800-EDTA (f) samples. 
TABLE 2: List of crystal parameters of OS samples obtained from XRD patterns.

\begin{tabular}{|c|c|c|c|c|}
\hline Sample & Type of crystal & $2 \theta$ (degree) & d-spacing $(\AA)$ & Crystallite size $(\AA)$ \\
\hline QNOS- & $\mathrm{CaCO}_{3}$ & 29.4 & 3.037 & 2.87 \\
\hline PP & $\mathrm{Ca}(\mathrm{OH})_{2}$ & 34.0 & 2.630 & 1.79 \\
\hline \multirow{3}{*}{ QNOS-PP-800 } & $\mathrm{CaCO}_{3}$ & 29.4 & 3.037 & 3.58 \\
\hline & $\mathrm{CaO}$ & 37.2 & 2.405 & 3.66 \\
\hline & $\mathrm{Ca}(\mathrm{OH})_{2}$ & 34.0 & 2.624 & 1.43 \\
\hline \multirow{3}{*}{ QNOS-PP-800-EDTA } & $\mathrm{CaCO}_{3}$ & 29.4 & 3.039 & 4.78 \\
\hline & $\mathrm{CaO}$ & 37.4 & 2.426 & 2.44 \\
\hline & $\mathrm{Ca}(\mathrm{OH})_{2}$ & 34.0 & 2.628 & 1.79 \\
\hline PYOS-PP & $\mathrm{CaCO}_{3}$ & 29.4 & 3.039 & 4.78 \\
\hline PYOS-PP-Na & $\mathrm{CaCO}_{3}$ & 29.4 & 3.039 & 7.17 \\
\hline \multirow{2}{*}{ PYOS-PP-Na-800 } & $\mathrm{CaCO}_{3}$ & 29.4 & 3.042 & 2.87 \\
\hline & $\mathrm{Ca}(\mathrm{OH})_{2}$ & 34.0 & 2.629 & 1.79 \\
\hline \multirow{2}{*}{ PYOS-PP-Na-750 } & $\mathrm{CaCO}_{3}$ & 29.4 & 3.040 & 14.33 \\
\hline & $\mathrm{Ca}(\mathrm{OH})_{2}$ & 34.0 & 2.629 & 2.87 \\
\hline \multirow{2}{*}{ PYOS-PP-Na-900 } & $\mathrm{CaCO}_{3}$ & 29.4 & 3.031 & 14.3 \\
\hline & $\mathrm{Ca}(\mathrm{OH})_{2}$ & 34.1 & 2.622 & 2.07 \\
\hline PYOS-PP-Na-800-EDTA & $\mathrm{CaCO}_{3}$ & 29.4 & 3.040 & 7.17 \\
\hline
\end{tabular}

TABLE 3: Specific surface area, pore volume, and pore diameter of OS samples.

\begin{tabular}{|c|c|c|c|c|c|c|}
\hline Sample & $\begin{array}{l}\text { BET surface } \\
\text { area }\left(\mathrm{m}^{2} / \mathrm{g}\right)\end{array}$ & $\begin{array}{l}\mathrm{t} \text {-plot micropore } \\
\text { area }\left(\mathrm{m}^{2} / \mathrm{g}\right)\end{array}$ & $\begin{array}{c}\text { t-plot external } \\
\text { surface area } \\
\left(\mathrm{m}^{2} / \mathrm{g}\right)\end{array}$ & $\begin{array}{l}\text { t-plot micropore } \\
\text { volume }\left(\mathrm{cm}^{3} / \mathrm{g}\right)\end{array}$ & $\begin{array}{c}\text { BJH adsorption } \\
\text { cumulative volume of } \\
\text { pores }^{*}\left(\mathrm{~cm}^{3} / \mathrm{g}\right)\end{array}$ & $\begin{array}{c}\text { BJH adsorption } \\
\text { average pore width } \\
(\mathrm{nm})\end{array}$ \\
\hline QNOS-PP & 10.2962 & 0.7658 & 9.5304 & 0.000170 & 0.043458 & 19.1191 \\
\hline $\begin{array}{l}\text { QNOS-PP- } \\
800\end{array}$ & 0.9719 & 0.0319 & 0.9399 & 0.000003 & 0.006084 & 27.5392 \\
\hline $\begin{array}{l}\text { QNOS-PP- } \\
\text { 800-EDTA }\end{array}$ & 4.7673 & - & - & - & 0.034279 & 29.7813 \\
\hline PYOS-PP & 1.3476 & 0.1504 & 1.1972 & 0.000039 & 0.008170 & 28.5818 \\
\hline $\begin{array}{l}\text { PYOS-PP- } \\
\mathrm{Na}-800\end{array}$ & 1.8008 & 0.2097 & 1.5911 & 0.000096 & 0.009444 & 24.0858 \\
\hline $\begin{array}{l}\text { PYOS-PP- } \\
\text { Na-800- } \\
\text { EDTA }\end{array}$ & 1.1372 & 0.2245 & 0.9127 & 0.000073 & 0.007769 & 31.9977 \\
\hline
\end{tabular}

* Between $1.7000 \mathrm{~nm}$ and $300.0000 \mathrm{~nm}$ width.

diameter of this material were augmented; however, the microcapillaries in the sample cannot be observed. The change in the surface area of QNOS-PP-800-EDTA sample may be due to some crystalline phases such as $\mathrm{CaO}$ and $\mathrm{Ca}(\mathrm{OH})_{2}$ being washed partially in the modification process. The increase in capillary diameter of QNOS-PP-800-EDTA sample also explains the increase in the $\mathrm{Cr}$ (VI) ions absorption ability of this material.

For OS samples collected in Phu Yen sea region, the presence of microcapillaries as well as larger capillary diameters has proved that $\mathrm{Cr}$ (VI) ions absorption ability of the OS samples in Phu Yen sea region was better than that of the OS samples in Quang Ninh sea region at the same treatment condition as discussed in the following.

3.1.4. pH of Zero Point Charge of Some Oyster Shell Samples. The $\mathrm{pH}$ of the zero point charge $\left(\mathrm{pH}_{\mathrm{zpc}}\right)$ for some OS samples is calculated from graphs of the dependence of final $\mathrm{pH}$ on the initial $\mathrm{pH}$ as shown in Figure 8 and listed in Table 4. The $\mathrm{pH}_{\mathrm{zpc}}$ indicates surface charge of material (positively or negatively); for example, at the $\mathrm{pH}<\mathrm{pH}_{\mathrm{zpc}}$, hydrogen ions (protons, $H+$ ) would be adsorbed more than other cations so that the other cations would be less adsorbed in the case of the negatively charged particle. On the other hand, if the surface is positively charged and $\mathrm{pH}$ is increased $\left(\mathrm{pH}>\mathrm{pH}_{\mathrm{zpc}}\right)$, anions will be less adsorbed as hydroxide ions are increased [14]. The $\mathrm{pH}_{\mathrm{zpc}}$ is basic for choosing the suitable $\mathrm{pH}$ for ions adsorption study of the materials. The data in Table 4 display that initial OS samples (PYOS-PP and QNOS-PP) have a quite high $\mathrm{pH}_{\mathrm{zpc}}$ value (9.68 and 9.15, respectively). After calcination, the $\mathrm{pH}_{\mathrm{zpc}}$ value of these samples was reduced maybe due to the partial decomposition of $\mathrm{CaCO}_{3}$ and $\mathrm{Ca}(\mathrm{OH})_{2}$ as discussed in XRD patterns (Section 3.1.2).

3.2. Morphology of Some Oyster Shell Samples. Figure 9 and Figure 1S are FESEM images of the OS samples at different magnifications. It is clear that there are few pores on the surface of the original OS samples (QNOS-PP and PYOS$\mathrm{PP})$. These samples are in sheet shape. After treatment with $\mathrm{NaClO} / \mathrm{NaOH}$ solution (PYOS-PP-Na), the shape of PYOS$\mathrm{PP}$ samples was changed due to the impaction of milling. The 


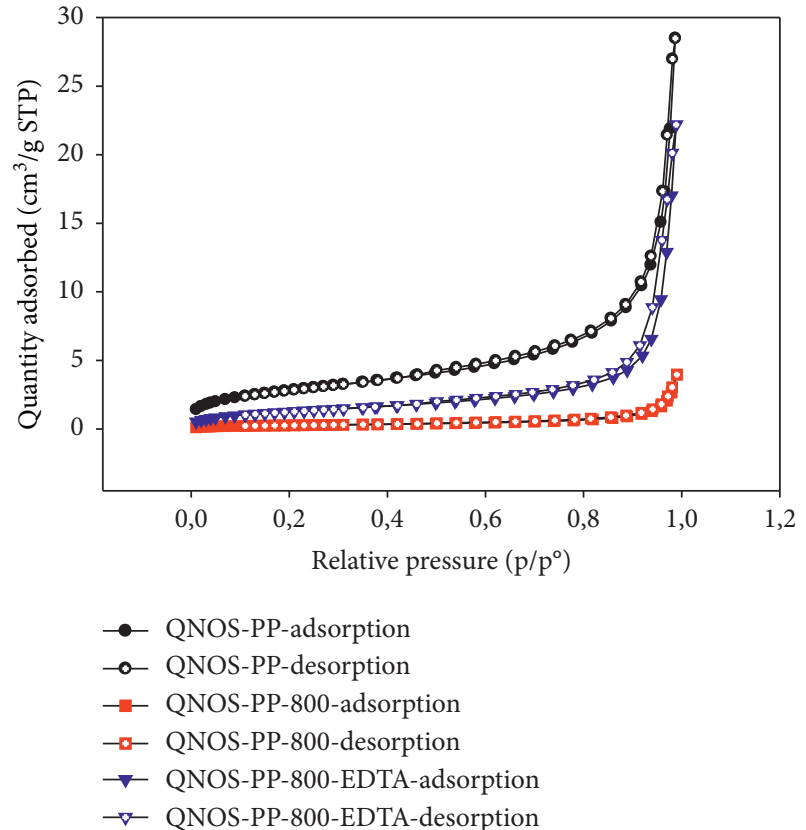

FIgURE 6: Nitrogen adsorption-desorption isothermal linear plots of QNOS-PP, QNOS-PP-800, and QNOS-PP-800-EDTA samples.

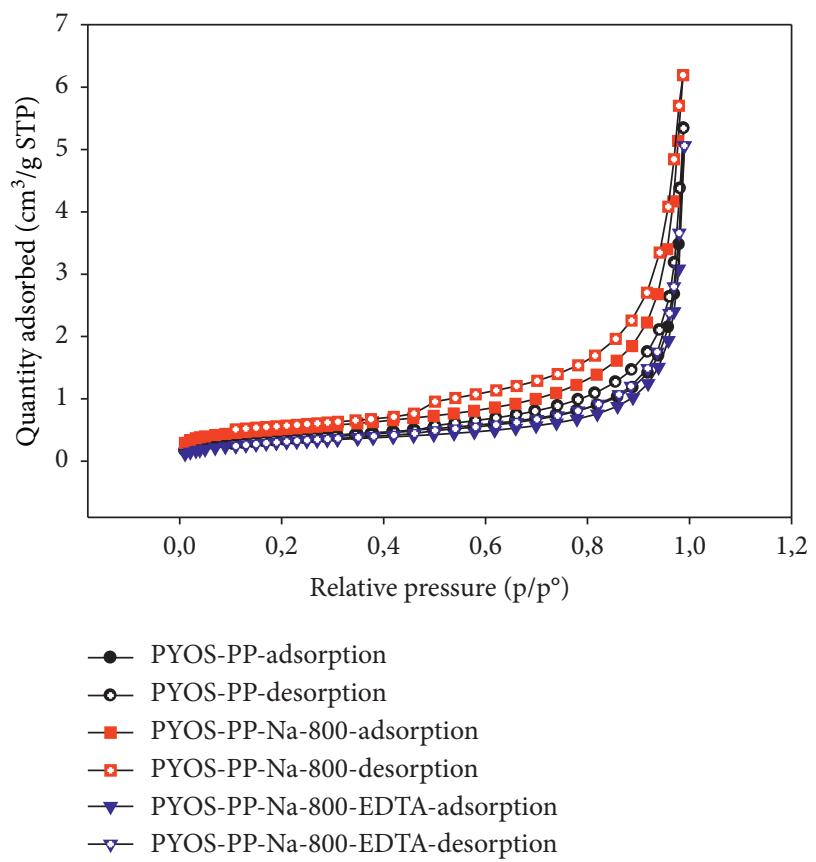

FIGURE 7: Nitrogen adsorption-desorption isothermal linear plots of PYOS-PP, PYOS-PP-Na-800, and PYOS-PP-Na-800-EDTA samples.

calcination process at 750,800 , and $900^{\circ} \mathrm{C}$ made the shape of PYOS-PP-Na become the cubic shape. There are more holes on the surface of PYOS-PP-Na-800 sample than PYOS-PPNa-750 and PYOS-PP-Na-900 samples. The OS samples calcined at $800^{\circ} \mathrm{C}$ (QN-PP-800 and PYOS-PP-Na-800) have more holes and porous structure than the original OS samples but after their modification by EDTA, the porous

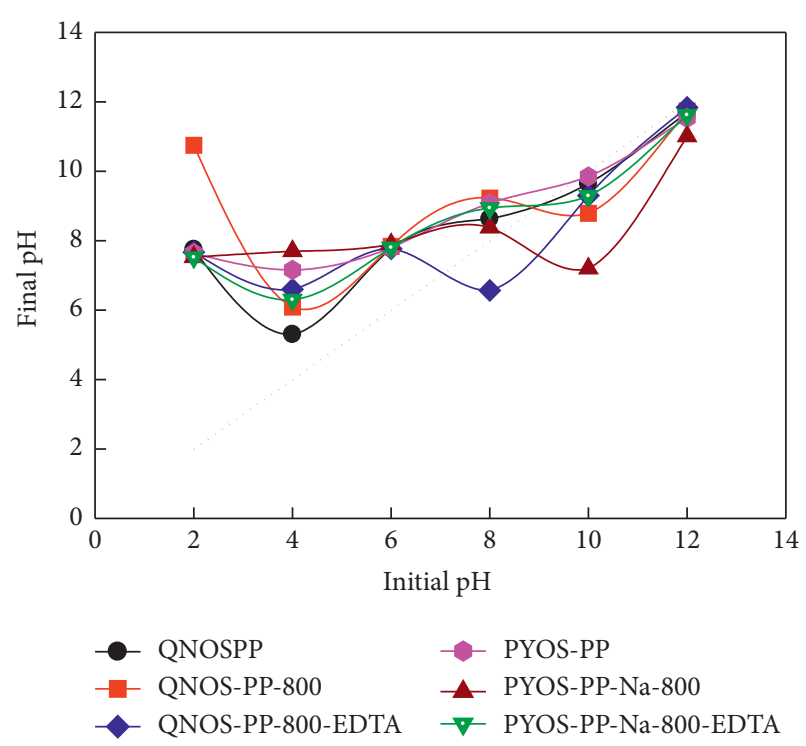

Figure 8: Graphs of dependence of final $\mathrm{pH}$ on initial $\mathrm{pH}$ of $\mathrm{OS}$ sample.

TABLE 4: $\mathrm{pH}_{\mathrm{zpc}}$ of some oyster shell samples.

\begin{tabular}{lc}
\hline Sample & $\mathrm{pH}_{\mathrm{zpc}}$ \\
\hline QNOS-PP & 9.15 \\
QNOS-PP-800 & 8.95 \\
QNOS-PP-800-EDTA & 7.04 \\
PYOS-PP & 9.68 \\
PYOS-PP-Na-800 & 8.27 \\
PYOS-PP-Na-800-EDTA & 9.05 \\
\hline
\end{tabular}

microstructure of QNOS-PP-800-EDTA and PYOS-PP-Na800-EDTA samples is clearly observed. This is why the $\mathrm{Cr}$ (VI) ion adsorption efficiency of modified OS samples is higher than that of original and calcined OS samples. Comparing two OS samples taken from two different geographical positions (Phu Yen and Quang Ninh sea regions), it can be seen that Phu Yen OS samples have a porous surface and a higher number of holes than Quang Ninh OS samples; hence the $\mathrm{Cr}$ (VI) ions adsorption efficiency of PY-OS samples is higher than that of QNOS samples.

Combining the results of IR, XRD, FESEM, and BET analysis, it can be suggested that EDTA molecules can be absorbed into the microholes onto the surface of OS samples or reacted with $\mathrm{Ca}(\mathrm{OH})_{2}$ and $\mathrm{CaO}$ in $\mathrm{OS}$ samples as described in Figure 2.

3.3. Evaluation of $\mathrm{Cr}$ (VI) Ions Adsorption Ability of Some Oyster Shell Types. Table 5 demonstrates removal percentage of $\mathrm{Cr}(\mathrm{VI})$ ions $(H)$ and the amount of $\mathrm{Cr}(\mathrm{VI})$ ion adsorbed per gram of adsorbent $(Q)$ for different investigated OS samples using 0.1 gram of OS adsorbent, the initial Cr (VI) ion concentration of $50 \mathrm{ppm}$, and the adsorption time of 2 hours.

As observed from Table 5, the Cr (VI) ions adsorption ability of PYOS particles treated with $\mathrm{NaOH} / \mathrm{NaClO}$ solution (sample no. 5) is higher than that of pretreated PYOS 


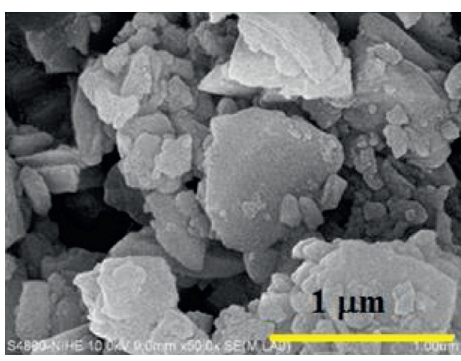

(a)

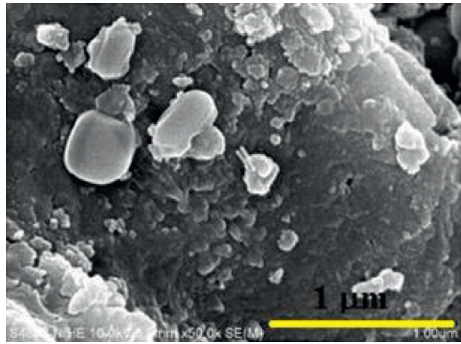

(d)

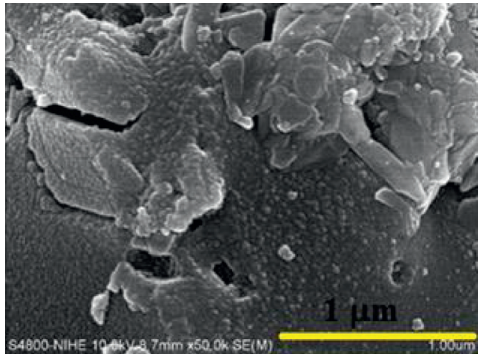

(g)

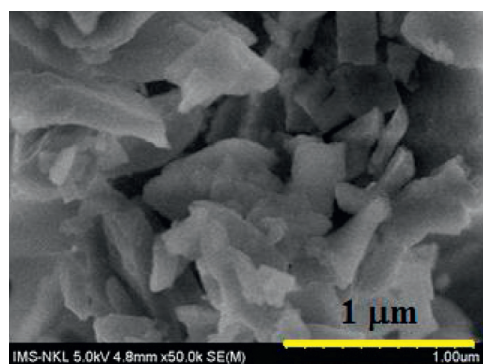

(b)

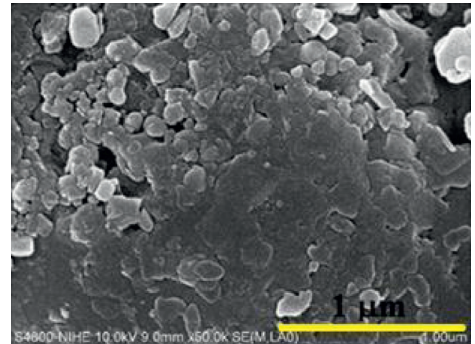

(e)

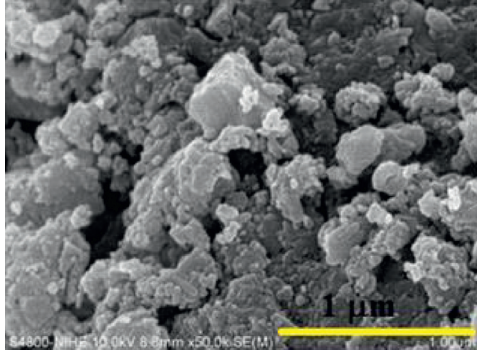

(h)

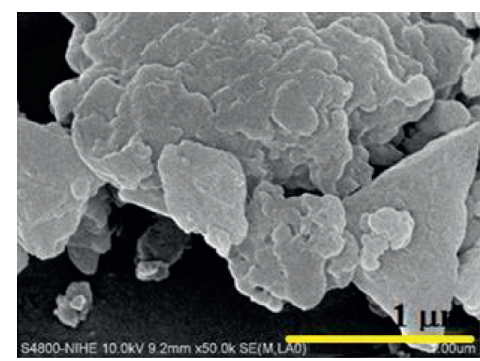

(c)

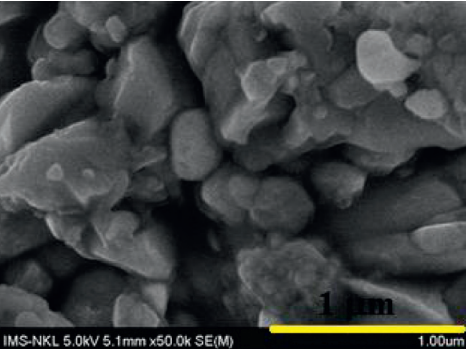

(f)

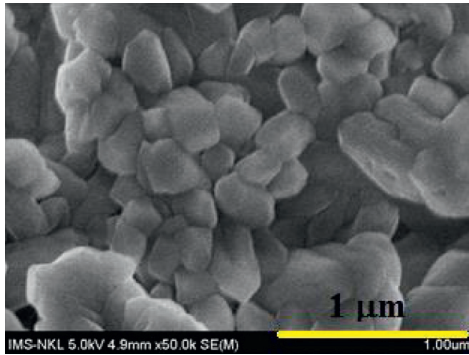

(i)

Figure 9: FESEM images of OS samples at the magnification of 50.000 times.

TABLE 5: Cr (VI) ions adsorption ability of oyster shell samples.

\begin{tabular}{lccc}
\hline No. & Sample & Q $(\mathrm{mg} / \mathrm{g})$ & $\mathrm{H}(\%)$ \\
\hline 1 & QNOS-PP & 14.90 & 29.80 \\
2 & QNOS-PP-800 & 19.50 & 39.00 \\
3 & QNOS-PP-800-EDTA & $\mathbf{2 8 . 8 0}$ & $\mathbf{5 7 . 6 0}$ \\
4 & PYOS-PP & 11.40 & 22.80 \\
5 & PYOS-PP-Na & 25.70 & 51.40 \\
6 & PYOS-PP-Na-750 & 11.77 & 23.60 \\
7 & PYOS-PP-Na-800 & $\mathbf{2 5 . 8 8}$ & $\mathbf{5 1 . 5 6}$ \\
8 & PYOS-PP-Na-900 & 19.02 & 38.04 \\
9 & PYOS-PP-Na-800-EDTA & $\mathbf{3 2 . 0 0}$ & $\mathbf{6 4 . 0 0}$
\end{tabular}

particles (sample no. 4). This confirms that treatment process is necessary to improve adsorption ability of the OS samples because sand, organic compounds, and impurities on the surface of OS particles were removed in the treatment process, leading to exposing the adsorption sites.

For further treatment, the initial OS and OS-Na samples were calcined at 750,800 , and $900^{\circ} \mathrm{C}$ to make a variation in their phase structure. At different temperatures, the $\mathrm{Cr}$ (VI) ions adsorption ability of PYOS samples was also varied significantly. This may be explained by the modification in structure of OS samples as impacted by calcination process at high temperature. According to XRD analysis results, the main composition in OS samples is $\mathrm{CaCO}_{3}$; under the impact of temperature, $\mathrm{CaCO}_{3}$ was degraded and converted to $\mathrm{CaO}[15,16]$. The release of carbon dioxide and existence of $\mathrm{CaO}$ phase in calcined OS samples can lead to the increase in porosity of these samples, resulting in the enhancement of metal ions adsorption ability. The temperature of $800^{\circ} \mathrm{C}$ is the most suitable for calcination process of PYOS samples to give a better $\mathrm{Cr}$ (VI) ions adsorption ability (samples no. 5, no. 6 , no. 7 , and no. 8 ).

Considering the effect of biodiversity on $\mathrm{Cr}$ (VI) ions adsorption ability by OS particles, the results in Table 5 also show that the OS samples in Phu Yen sea region have adsorption ability better than the OS samples in Quang Ninh sea region (samples no.1 and no. 4). This proves that the differences in geographical position of two sea regions and aquaculture conditions of oysters can result in the formation and characteristics of OS samples as shown by their BET parameters and FESEM images (Sections 3.2.2 and 3.2.3 before).

EDTA also has a positive effect on the Cr (VI) ions adsorption ability by OS samples thanks to the formation of the complex between EDTA and Cr (VI) ions. The $\mathrm{H}$ and $\mathrm{Q}$ of samples no. 3 and no. 9 are 1.24-1.48 times larger than those of the samples no. 2 and no. 7. The effect of EDTA on the heavy metal adsorption ability was also proved by Min et al. [16]. 
From the obtained results, the PYOS-PP-Na-800-EDTA sample with the highest $\mathrm{Cr}$ (VI) ions adsorption ability is selected for further studies.

3.4. Effect of Some Experiment Conditions on Cr (VI) Ions Adsorption Ability of Oyster Shell Samples. Effect of some experiment conditions on the $\mathrm{Cr}$ (VI) ions adsorption ability of OS samples was carried out on PYOS-PP-Na-800-EDTA sample. The changes of $\mathrm{pH}$ solution, time adsorption, absorbent weight, and initial concentration of $\mathrm{Cr}$ (VI) ions solution are investigated. The results of removal percent of $\mathrm{Cr}(\mathrm{VI})$ ions (H) and amount of $\mathrm{Cr}(\mathrm{VI})$ ions adsorbed per gram of adsorbent $(Q)$ are listed in Table 6.

3.4.1. Effect of $p H$ of Solution. The results in Table 6 show that when changing the $\mathrm{pH}$ of solutions and fixing other factors (the initial $\mathrm{Cr}$ (VI) ions concentration of $10 \mathrm{ppm}$, the adsorption time of $120 \mathrm{~min}$, and the absorbent weight of 0.2 grams), the Cr (VI) ions adsorption ability of the PYOS-PPNa-800-EDTA sample was also affected significantly and reached the highest $\mathrm{H}$ and $\mathrm{Q}$ value in solution $\mathrm{pH}$ of 6 $(2.36 \mathrm{mg} / \mathrm{g}$ and $47.10 \%$, respectively). In solution $\mathrm{pH}$ range from 2 to 6 , the $\mathrm{Cr}$ (VI) ions are in form of acid chromate ions $\left(\mathrm{HCr}_{2} \mathrm{O}_{7}^{-}\right.$and $\left.\mathrm{HCrO}_{4}^{-}\right)$. When the $\mathrm{pH}$ of solutions increases from 6 to 7 , the $\mathrm{Cr}$ (VI) ions will be changed into $\mathrm{Cr}_{2} \mathrm{O}_{7}{ }^{2-}$ and $\mathrm{CrO}_{4}{ }^{2-}$. In $\mathrm{pH} 7$ solution, $\mathrm{Cr}(\mathrm{VI})$ ions are only in $\mathrm{CrO}_{4}{ }^{2-}$ form and in solution $\mathrm{pH}$ higher $7, \mathrm{Cr}(\mathrm{VI})$ ions will be in the form of $\mathrm{Cr}(\mathrm{OH})_{6}$. In case of $\mathrm{pH}<\mathrm{pH}_{\mathrm{pzc}}$ (9.05), the PYOS-PP-Na-800-EDTA sample is positively charged; therefore, the anions adsorption ability by this sample was increased significantly [14]. Specifically, the $\mathrm{CrO}_{4}{ }^{2-}$ and $\mathrm{Cr}_{2} \mathrm{O}_{7}{ }^{2-}$ ions can be absorbed onto the surface of PYOS-PP$\mathrm{Na}-800$-EDTA sample better than $\mathrm{HCr}_{2} \mathrm{O}_{7}^{-}$and $\mathrm{HCrO}_{4}{ }^{-}$ ions; thus, $\mathrm{pH} 6$ is the most suitable $\mathrm{pH}$ for the $\mathrm{Cr}$ (VI) ions adsorption study by PYOS-PP-Na-800-EDTA sample. The same results were reported by Nagashanmugam et al. [17].

3.4.2. Effect of Adsorption Time. Adsorption time influences strongly the $\mathrm{Cr}$ (VI) ions adsorption ability of the PYOS-PPNa-800-EDTA sample as fixing other adsorption factors (the initial $\mathrm{Cr}$ (VI) ions concentration of $10 \mathrm{ppm}$, the $\mathrm{pH}$ of 6 , and the absorbent weight of 0.2 grams). It can be seen that the $H$ and $Q$ of $\mathrm{Cr}(\mathrm{VI})$ ions are increased as rising adsorption time. This result indicates that the adsorption of $\mathrm{Cr}$ (VI) ions onto PYOS-PP-Na-800-EDTA sample requires a long stirring time. However, the $H$ and $Q$ were augmented extremely at the adsorption time of $120 \mathrm{~min}$, and they were then varied slowly. The adsorbent with many active sites adsorbed a large part of $\mathrm{Cr}$ (VI) ions in the solution for first $120 \mathrm{~min}$. While adsorption time is over $120 \mathrm{~min}$, the occupation of these adsorption sites by $\mathrm{Cr}$ (VI) ions causes the reduction of the availability of active sites in the PYOS-PP-Na-800-EDTA sample. On the other hand, there is a possibility of release back of Cr (VI) ions from the surface of PYOS-PP-Na-800EDTA sample to the solution due to the weak interaction between the adsorbent and the ion target. Therefore, the period of $120 \mathrm{~min}$ was considered to reach adsorption equilibrium or equilibrium time.

3.4.3. Effect of Absorbent Weight. The results in Table 6 also prove that when changing the weight of the absorbent and fixing other factors (the initial $\mathrm{Cr}$ (VI) ions concentration of $10 \mathrm{ppm}$, the $\mathrm{pH}$ of 6 , and the time contact of $120 \mathrm{~min}$ ), the $\mathrm{Cr}$ (VI) ions adsorption ability of PYOS-PP-Na-800-EDTA sample was increased because the higher volume of materials, the more voids to increase the adsorption ability of $\mathrm{Cr}$ (VI) ions into the adsorption material.

3.4.4. Effect of Initial Cr (VI) Ions Concentration. The effect of initial concentration on the $\mathrm{Cr}$ (VI) ions adsorption ability of PYOS-PP-Na-800-EDTA sample is carried out at condition of $\mathrm{pH} 6$ with adsorption time of $120 \mathrm{~min}$ and the adsorbent weight of 0.2 grams. The obtained results described in Table 6 show that the $Q$ value of sample was increased as rising initial $\mathrm{Cr}(\mathrm{VI})$ ions concentration.

3.5. Adsorption Isotherms of Cr (VI) Ions Adsorption Process Using Oyster Shell Samples and Error Analysis. Figure 10 and Table 7 display the parameters for plotting Langmuir, Freundlich, Temkin, and Dubinin-Radushkevich adsorption isotherms of $\mathrm{Cr}$ (VI) ions using the PYOS-PP-Na-800EDTA sample. The process of $\mathrm{Cr}$ (VI) ions adsorption by PYOS-PP-Na-800-EDTA sample is followed to the Langmuir isotherm model with the highest correlation coefficient, $R^{2}=0.9943$ (Table 8 ), which means that on the outer surface of OS samples formed a monolayer of adsorbed molecules and no further adsorption took place after that. The separation factor (also called equilibrium parameter), $R_{\mathrm{L}}=0.4988<1$, indicates that the equilibrium adsorption was favorable. The maximum adsorption capacity $\left(Q_{0}\right)$ of absorbent for the removal of $\mathrm{Cr}$ (VI) ions is $769.231 \mathrm{mg} / \mathrm{g}$. The Freundlich isotherm model also shows a relatively high correlation coefficient of 0.9767 but the adsorption intensity $n=0.971<1$; hence the sorption process is unfavorable (Table 8). The two other models indicate a lower value of $R^{2}$ and constants such as $B=4.0698 \mathrm{~J} / \mathrm{mol}$ and $E=0.80 \mathrm{~kJ} / \mathrm{mol}$ expressing physical adsorption process of PYOS-PP-Na-800 sample for Cr (VI) ions (Table 8). The Langmuir isotherm model was shown to be the best fitting for adsorption of $\mathrm{Cr}$ (VI) ions and $\mathrm{Cu}$ (II) [9].

The good Cr (VI) ions adsorption ability of oyster shell is a sign for the effectiveness regeneration of oyster shell waste as absorbent. The oyster shell sample after calcination and modification with EDTA is a promising absorbent material for the removal of heavy metal ions in aqueous solution, especially the anions in aqueous solutions.

Table 9 demonstrates the result of error analysis of the $\mathrm{Cr}$ (VI) ions adsorption isotherms models using various methods: $R^{2}$ (correlation coefficient), SSE (sum of square errors), MSE (mean square error), and RMSE (root mean square error). As can be seen, the Langmuir isotherms model has the highest correlation coefficient and smallest errors, which again confirms that this model fits to the adsorption 
TABLE 6: Effect of some experiment conditions on Cr (VI) ions adsorption ability of PYOS-PP-Na-800-EDTA sample.

\begin{tabular}{|c|c|c|c|c|c|c|c|c|c|c|c|}
\hline \multicolumn{3}{|c|}{$\mathrm{pH}$ of solution } & \multicolumn{3}{|c|}{ Adsorption time } & \multicolumn{3}{|c|}{ Absorbent weight } & \multicolumn{3}{|c|}{ Initial Cr (VI) ions concentration } \\
\hline $\mathrm{pH}$ & $Q(\mathrm{mg} / \mathrm{g})$ & $H(\%)$ & Time (min) & $Q(\mathrm{mg} / \mathrm{g})$ & $H(\%)$ & $\mathrm{m}_{\mathrm{os}}(\mathrm{g})$ & $Q(\mathrm{mg} / \mathrm{g})$ & $H(\%)$ & $C_{\mathrm{o}}(\mathrm{ppm})$ & $Q(\mathrm{mg} / \mathrm{g})$ & $H(\%)$ \\
\hline 2 & 0.80 & 16.00 & 20 & 0.68 & 13.61 & 0.1 & 1.65 & 29.30 & 3 & 1.65 & 55.00 \\
\hline 3 & 1.30 & 26.00 & 30 & 0.87 & 17.30 & 0.2 & 1.73 & 34.50 & 7 & 3.88 & 55.43 \\
\hline 4 & 1.65 & 33.00 & 45 & 1.10 & 21.90 & 0.5 & 2.12 & 42.30 & 8 & 4.35 & 54.48 \\
\hline 5 & 2.14 & 42.70 & 60 & 1.54 & 30.80 & 0.6 & 2.27 & 45.30 & 10 & 5.20 & 52.00 \\
\hline 6 & 2.36 & 47.10 & 90 & 1.65 & 33.00 & 0.8 & 2.49 & 49.70 & 15 & 8.77 & 58.47 \\
\hline \multirow[t]{3}{*}{7} & 0.28 & 5.60 & 120 & 2.66 & 53.10 & 1.0 & 2.92 & 58.30 & & & \\
\hline & & & 150 & 2.81 & 56.20 & & & & & & \\
\hline & & & 180 & 2.84 & 56.80 & & & & & & \\
\hline
\end{tabular}

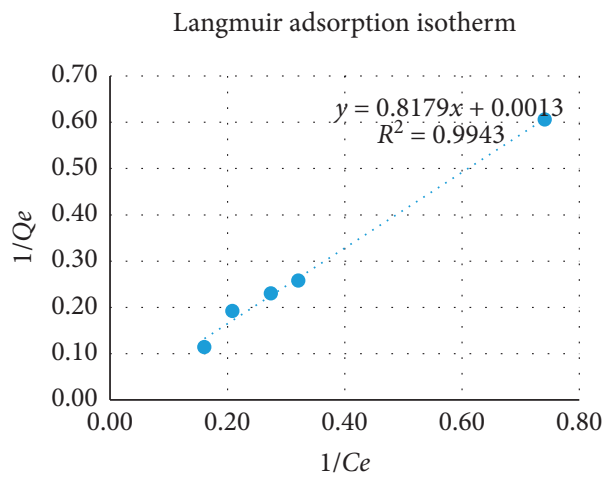

(a)

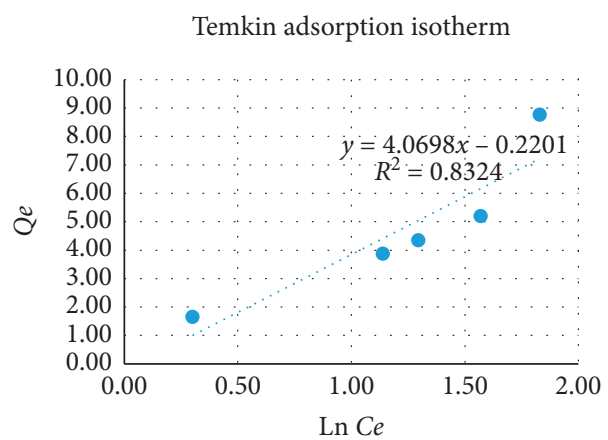

(c)

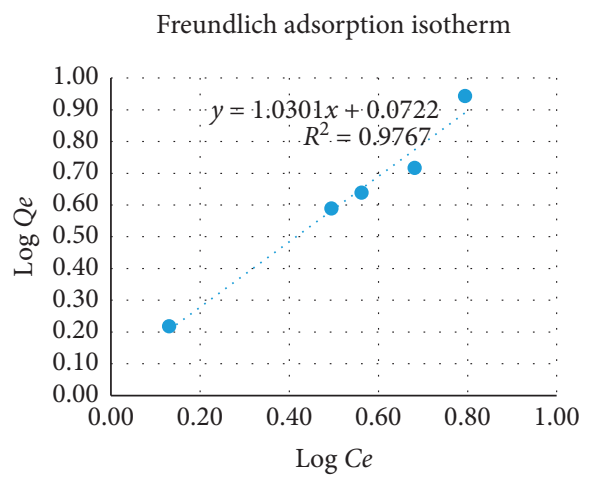

(b)

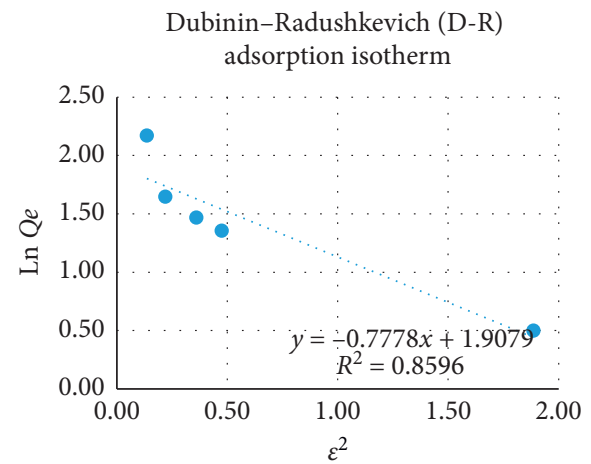

(d)

Figure 10: Different isotherm models with their equations and correlation coefficient values. (a) Langmuir adsorption isotherm. (b) Freundlich adsorption isotherm. (c) Temkin adsorption isotherm. (d) Dubinin-Radushkevich (D-R) adsorption isotherm.

TABle 7: Parameters for plotting Langmuir, Freundlich, Temkin, and Dubinin-Radushkevich adsorption isotherms of Cr (VI) ions using oyster shell samples.

\begin{tabular}{lcccccccccc}
\hline No. & $\mathrm{C}_{0}(\mathrm{mg} / \mathrm{L})$ & $C_{\mathrm{e}}(\mathrm{mg} / \mathrm{L})$ & $1 / C_{\mathrm{e}}$ & $\log C_{\mathrm{e}}$ & $\operatorname{Ln} C_{\mathrm{e}}$ & $Q_{\mathrm{e}}(\mathrm{mg} / \mathrm{g})$ & $1 / Q_{\mathrm{e}}$ & $\log Q_{\mathrm{e}}$ & $\operatorname{Ln} Q_{\mathrm{e}}$ & $\varepsilon^{2}$ \\
\hline 1 & 3 & 1.35 & 0.74 & 0.13 & 0.30 & 1.65 & 0.61 & 0.22 & 0.50 & 1.89 \\
2 & 7 & 3.12 & 0.32 & 0.49 & 1.14 & 3.88 & 0.26 & 0.59 & 1.36 & 0.47 \\
3 & 8 & 3.65 & 0.27 & 0.56 & 1.29 & 4.35 & 0.23 & 0.64 & 1.47 & 0.36 \\
4 & 10 & 4.8 & 0.21 & 0.68 & 1.57 & 5.20 & 0.19 & 0.72 & 1.65 & 0.22 \\
5 & 15 & 6.23 & 0.16 & 0.79 & 1.83 & 8.77 & 0.11 & 0.94 & 2.17 & 0.14 \\
\hline
\end{tabular}

mechanism of ion Cr (VI) ions into the selected oyster shell samples. The Freundlich model also shows relatively high $R^{2}$ and small errors. On the other hand, the Temkin model exhibits the lowest correlation coefficient and highest error, which means the isotherms ion $\mathrm{Cr}$ (VI) ions adsorption using oyster shell samples does not follow this model. 
TABle 8: Langmuir, Freundlich, Temkin, and Dubinin-Radushkevich isotherm constants for the adsorption of Cr (VI) ions using oyster shell.

\begin{tabular}{|c|c|c|c|c|c|c|c|}
\hline \multicolumn{4}{|c|}{ Langmuir constant } & \multicolumn{4}{|c|}{ Freundlich constant } \\
\hline$Q_{0}(\mathrm{mg} / \mathrm{g})$ & $K_{\mathrm{L}}(\mathrm{L} / \mathrm{mg})$ & $R_{\mathrm{L}}$ & $R^{2}$ & $1 / \mathrm{n}$ & $\mathrm{n}$ & $k_{\mathrm{f}}(\mathrm{mg} / \mathrm{g})$ & $R^{2}$ \\
\hline 769.231 & 0.0016 & 0.4988 & 0.9943 & 1.030 & 0.971 & 1.181 & 0.9767 \\
\hline \multicolumn{4}{|c|}{ Temkin constant } & \multicolumn{4}{|c|}{ Dubinin-Radushkevich constant } \\
\hline$A_{\mathrm{T}}(\mathrm{L} / \mathrm{mg})$ & $b_{\mathrm{T}}$ & $\mathrm{B}(\mathrm{J} / \mathrm{mol})$ & $R^{2}$ & $Q_{s}(\mathrm{mg} / \mathrm{g})$ & $\mathrm{K}_{\mathrm{ad}}\left(\mathrm{mol}^{2} / \mathrm{kJ}^{2}\right)$ & $\mathrm{E}(\mathrm{kJ} / \mathrm{mol})$ & $R^{2}$ \\
\hline 0.9474 & 608.770 & 4.0698 & 0.8324 & 6.739 & 0.778 & 0.80 & 0.8596 \\
\hline
\end{tabular}

TABLe 9: Error analysis of $R^{2}$, SSE, MSE, and RMSE for Cr (VI) ions adsorption according to various isotherms models.

\begin{tabular}{|c|c|c|c|c|}
\hline Adsorption isotherm equation & $R^{2}$ & SSE & MSE & RMSE \\
\hline Langmuir & 0.994 & 0.00082 & 0.00016 & 0.01283 \\
\hline Freundlich & 0.977 & 0.00645 & 0.00129 & 0.03592 \\
\hline Temkin & 0.832 & 4.50704 & 0.90141 & 0.94943 \\
\hline D-R & 0.860 & 0.20611 & 0.04122 & 0.20303 \\
\hline
\end{tabular}

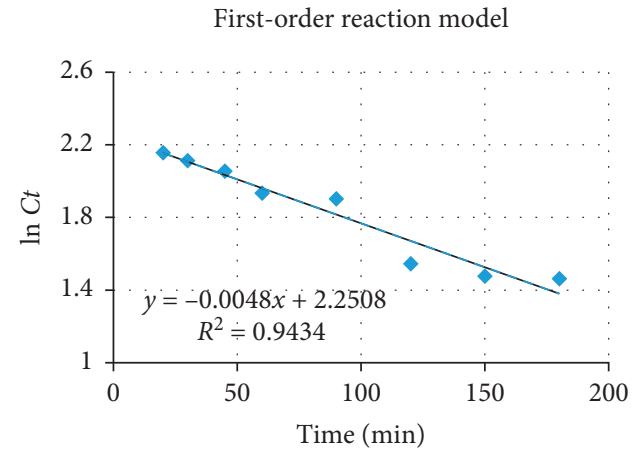

(a)

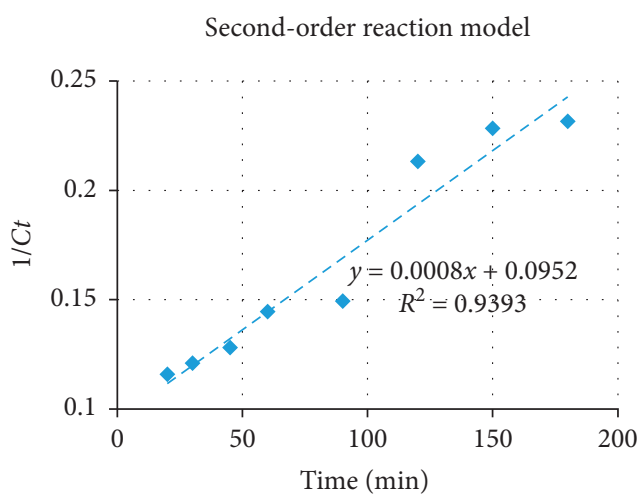

(c)

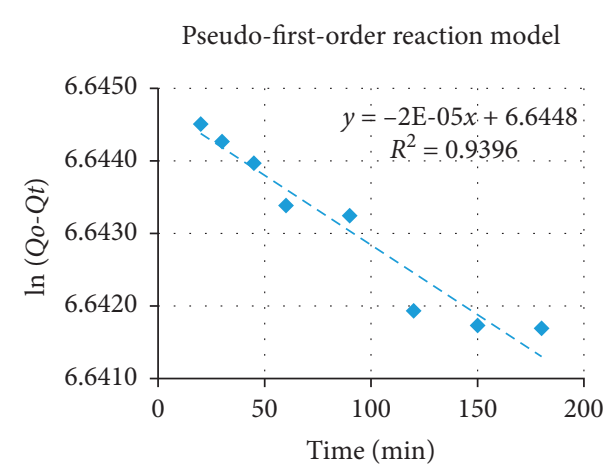

(b)

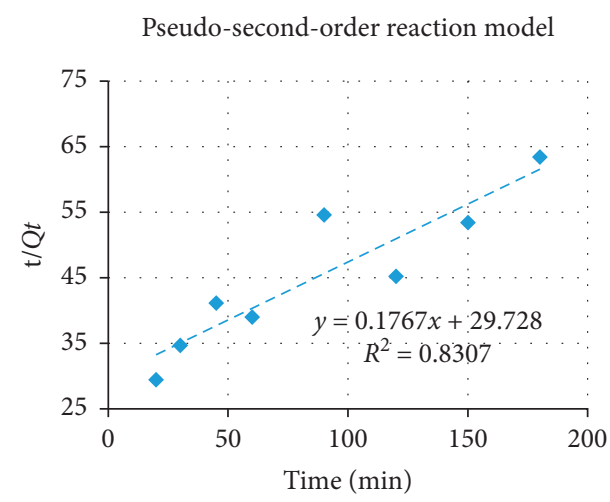

(d)

FIGURE 11: Different linear kinetic models of Cr (VI) ions adsorption according to their equations and correlation coefficient values. (a) First-order reaction model. (b) Pseudo-first-order reaction model. (c) Second-order reaction model. (d) Pseudo-second-order reaction model.

\subsection{Adsorption Kinetics of Cr (VI) Ions Adsorption Process} Using Oyster Shell Samples. The adsorption kinetics of $\mathrm{Cr}$ (VI) ions adsorption process are studied and four linear kinetic models are used in this work as presented in Figure 11. As can be seen in Figure 11, the first-order reaction model fitting the adsorption kinetic of $\mathrm{Cr}$ (VI) ions adsorption process is more suitable with the correlation coefficient $R^{2}$ of 0.9434 . The pseudo-first-order reaction and second-order reaction models also indicate relatively high values of $R^{2}$, approximately 0.94 . The pseudo-second-order
TABLE 10: Error analysis of $R^{2}$, SSE, MSE, and RMSE for Cr (VI) ions adsorption according to various kinetic models.

\begin{tabular}{lcccc}
\hline Model & $R^{2}$ & SSE & MSE & RMSE \\
\hline First-order & 0.9434 & 0.03367718 & 0.00420965 & 0.06488180 \\
$\begin{array}{l}\text { Pseudo-first- } \\
\text { order }\end{array}$ & 0.9396 & 0.00000059 & 0.00000007 & 0.00027147 \\
$\begin{array}{l}\text { Second-order } \\
\begin{array}{l}\text { Pseudo- } \\
\text { second-order }\end{array}\end{array}$ & 0.9393 & 0.00107378 & 0.00013422 & 0.01158544 \\
\hline
\end{tabular}



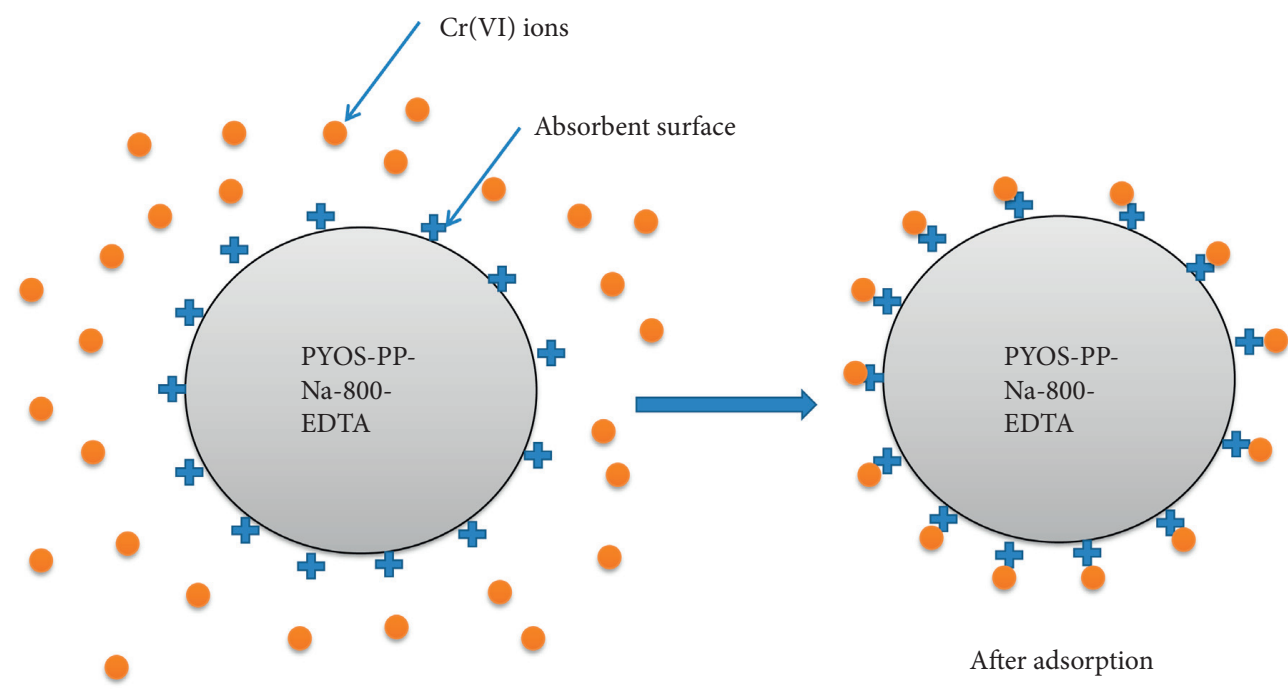

After adsorption

Before adsorption

FIgURE 12: Proposed mechanism of the adsorption of Cr (VI) ions on the PYOS-PP-Na-800-EDTA absorbent.

reaction model, on the other hand, shows a lower correlation coefficient, $R^{2}$ of 0.8307 . For the regression coefficient evaluation using the square errors (as listed in Table 10), it can be seen that the pseudo-first-order kinetic model exhibits the smallest error. The errors of first-order model and second-order model are also relatively small. Based on the square errors, it is confirmed that pseudo-first-order kinetic model is complied with the $\mathrm{Cr}$ (VI) ions adsorption process by using oyster shell sample.

Based on the results of adsorption isotherms and kinetics, an adsorption mechanism of $\mathrm{Cr}$ (VI) ions by oyster shell can be recommended as presented in Figure 12.

\section{Conclusion}

From the results in this study, we can conclude that the characteristics and $\mathrm{Cr}$ (VI) ions adsorption ability of two kinds of oyster shell (OS) samples collected at two unlike sea regions in Vietnam are clearly different. The Phu Yen OS samples have a porous surface and holes more than the Quang Ninh OS samples; hence the Cr (VI) ions adsorption ability of PY-OS samples is higher than that of QNOS samples. This shows that biodiversity can influence the structure of the materials collected at the different geographical positions. The calcination and modification of OS samples with EDTA are necessary for enhancement of $\mathrm{Cr}$ (VI) ions adsorption ability of OS samples. The factors such as $\mathrm{pH}$ solution, adsorption time, adsorbent weight, and initial Cr (VI) ions concentration obviously affect $\mathrm{Cr}$ (VI) ions adsorption efficiency of treated OS sample. The solution $\mathrm{pH}$ of 6 is the most suitable to remove $\mathrm{Cr}$ (VI) ions by using treated OS samples and the $\mathrm{Cr}$ (VI) ions adsorption efficiency is increased with rising adsorption time, adsorbent weight, and initial $\mathrm{Cr}$ (VI) ions concentration. The Langmuir isotherm model with the highest correlation coefficient $\left(R^{2}\right.$ of 0.9943$)$ and the lowest SSE, MSE, and RMSE is the most suitable for fitting the $\mathrm{Cr}$ (VI) ions adsorption by treated OS samples in aqueous solution. The maximum adsorption capacity of oyster shell absorbent for the removal of $\mathrm{Cr}$ (VI) ions is $769.231 \mathrm{mg} / \mathrm{g}$. The first-order reaction model is the best for studying the adsorption kinetic of Cr (VI) ions adsorption process. The treated OS samples are promising absorbents for removal of heavy metal ions in aqueous solution.

\section{Abbreviations}

\section{BET: Brunauer-Emmett-Teller}

DCP: 1,5-Diphenylcarbazide

EDTA: Ethylenediaminetetraacetic acid

FESEM: Field emission scanning electron microscopy

IR: Infrared

NP: $\quad$ Nacreous

OS: $\quad$ Oyster shell

PP: $\quad$ Prismatic

PYOS: Oyster shell samples collected at Phu Yen province sea

QNOS: Oyster shell samples collected at Quang Ninh province sea

XRD: X-ray diffraction

UV-Vis: Ultraviolet-visible.

\section{Data Availability}

The data used to support the findings of this study are included within the article.

\section{Conflicts of Interest}

The authors declare that they have no conflicts of interest. 


\section{Supplementary Materials}

Table 1S: position of main peaks in FTIR spectra of OS samples. Figure 1S: FESEM images of OS samples at the magnification of 200000 times. (Supplementary Materials)

\section{References}

[1] D. C. Sharma and C. F. Forster, "Column studies into the adsorption of chromium (VI) using sphagnum moss peat," Bioresource Technology, vol. 52, no. 3, pp. 261-267, 1995.

[2] S. Asaoka, T. Yamamoto, S. Kondo, and S. Hayakawa, "Removal of hydrogen sulfide using crushed oyster shell from pore water to remediate organically enriched coastal marine sediments," Bioresource Technology, vol. 100, no. 18, pp. 4127-4132, 2009.

[3] A. Z. Oo, S. Sudo, K. T. Win, A. Shibata, and T. Gonai, "Influence of pruning waste biochar and oyster shell on $\mathrm{N} 2 \mathrm{O}$ and CO 2 emissions from Japanese pear orchard soil," Heliyon, vol. 4, no. 3, Article ID e00568, 2018.

[4] D. Alidoust, M. Kawahigashi, S. Yoshizawa, H. Sumida, and M. Watanabe, "Mechanism of cadmium biosorption from aqueous solutions using calcined oyster shells," Journal of Environmental Management, vol. 150, no. 1, pp. 103-110, 2015.

[5] T. Hao-Cheng, L. Shang-Lien, and K. Jeff, "Using pretreated waste oyster and clam shells and microwave hydrothermal treatment to recover boron from concentrated wastewater," Bioresource Technology, vol. 102, no. 17, pp. 7802-7806, 2011.

[6] Y. Yu, R. Wu, and M. Clark, "Phosphate removal by hydrothermally modified fumed silica and pulverized oyster shell," Journal of Colloid and Interface Science, vol. 350, no. 2, pp. 538-543, 2010.

[7] A. F. Hassan and R. Hrdina, "Chitosan/nanohydroxyapatite composite based scallop shells as an efficient adsorbent for mercuric ions: static and dynamic adsorption studies," International Journal of Biological Macromolecules, vol. 109, no. 1, pp. 507-516, 2018.

[8] L. Jinshan, L. Zhangyang, L. Xibao, X. Haitao, and L. Xiaoyong, "Recycling of shell wastes into nanosized calcium carbonate powders with different phase compositions," Journal of Cleaner Production, vol. 92, pp. 223-229, 2015.

[9] W. Qiong, C. Jie, C. Malcolm, and Y. Yan, "Adsorption of copper to different biogenic oyster shell structures," Applied Surface Science, vol. 311, pp. 264-272, 2014.

[10] H. Luo, G. Huang, X. Fu et al., "Waste oyster shell as a kind of active filler to treat the combined wastewater at an estuary," Journal of Environmental Sciences, vol. 25, no. 10, pp. 20472055, 2013.

[11] Y. Chen, J. Xu, Z. Lv, R. Xie, L. Huang, and J. Jiang, "Impacts of biochar and oyster shells waste on the immobilization of arsenic in highly contaminated soils," Journal of Environmental Management, vol. 217, pp. 646-653, 2018.

[12] C. Gong, L. Qionghui, S. Zhan, S. Sheng, and F. Jie, "Preparation, optimization, and application of sustainable ceramsite substrate from coal fly ash/waterworks sludge/oyster shell for phosphorus immobilization in constructed wetlands," Journal of Cleaner Production, vol. 175, pp. 572-581, 2018.

[13] H. Ting-Chu, "Experimental assessment of adsorption of $\mathrm{Cu}^{2+}$ and $\mathrm{Ni}^{2+}$ from aqueous solution by oyster shell powder," Journal of Hazardous Materials, vol. 171, pp. 995-1000, 2009.

[14] M. Boumediene, H. Benaïssa, B. George, St. Molina, and A. Merlin, "Effects of $\mathrm{pH}$ and ionic strength on methylene blue removal from synthetic aqueous solutions by sorption onto orange peel and desorption study," Journal of Materials and Environmental Science, vol. 9, no. 6, pp. 1700-1711, 2018.

[15] H.-B. Kwon, C.-W. Lee, B.-S. Jun, J.-d. Yun, S.-Y. Weon, and B. Koopman, "Recycling waste oyster shells for eutrophication control," Resources, Conservation and Recycling, vol. 41, no. 1, pp. 75-82, 2004.

[16] W. Min, W. Zhuqing, Z. Xiaohong, and L. Shikun, "Efficient removal of heavy metal ions in wastewater by using a novel alginate-EDTA hybrid aerogel," Applied Sciences, vol. 9, p. 547, 2019.

[17] K. B. Nagashanmugam, "Evaluation of chromium (VI) removal by carbons derived from Sesamum indicum oil cake," Journal of the Southern African Institute of Mining and Metallurgy, vol. 118, no. 4, pp. 369-376, 2018. 